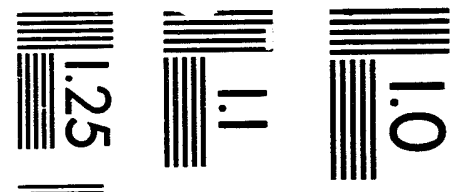

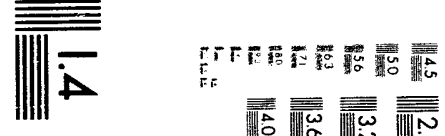

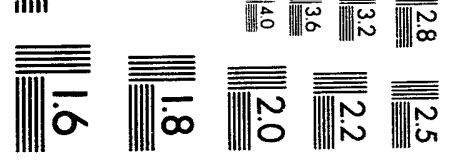



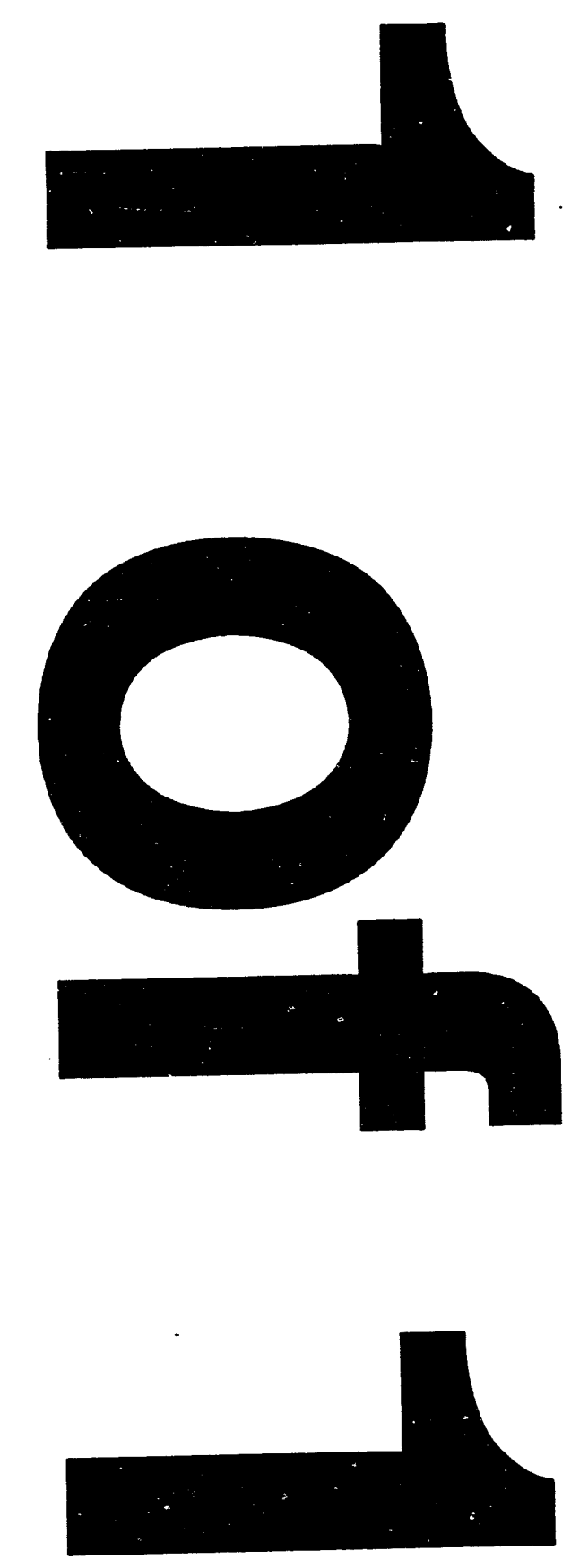
ORNL/TM-12391

Dist. Category UC-530

\title{
A NONLINEAR DYNAMIC MODEL OF A ONCE-THROUGH, HELICAL-COIL STEAM GENERATOR
}

\author{
M. A. Abdalla \\ Oak Ridge Associated Universities* \\ P.O. Box 117 \\ Oak Ridge, Tennessee 37831-0117
}

Date Published-July 1993

\author{
Prepared by the \\ OAK RIDGE NATIONAL LABORATORY \\ Oak Ridge, Tennessee 37831-6285 \\ managed by \\ MARTIN MARIETTA ENERGY SYSTEMS, INC. \\ for the \\ U.S. DEPARTMENT OF ENERGY \\ under contract DE-AC05-84OR21400
}

\footnotetext{
* This research was supported in part by an appointment to the U.S. Department of Energy Laboratory Cooperative Postgraduate Research Training Program administered by the Oak Ridge Institute for Science and Education.
} 


\section{CONTENTS}

Page

LIST OF FIGURES $\ldots \ldots \ldots \ldots \ldots \ldots \ldots \ldots$

ABSTRACT $\ldots \ldots \ldots \ldots \ldots \ldots \ldots \ldots \ldots \ldots \ldots \ldots$ vii

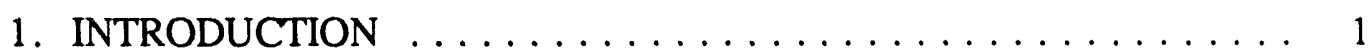

2. STEAM GENERATOR DESCRIPTION $\ldots \ldots \ldots \ldots \ldots$

3. MATHEMATICAL FORMULATION OF THE MODEL . . . . . . . . . 4

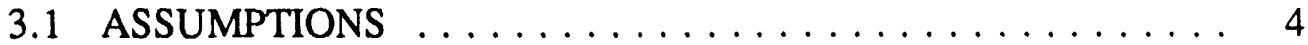

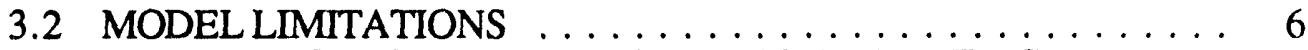

3.3 GENERAL CONSERVATION OF MASS AND ENERGY

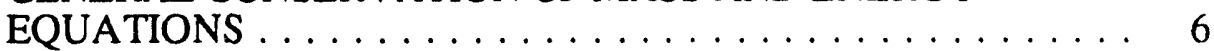

3.3.1 Conservation of energy $\ldots \ldots \ldots \ldots \ldots \ldots \ldots \ldots \ldots$

3.3.2 Conservation of mass $\ldots \ldots \ldots \ldots \ldots \ldots \ldots$

3.4 SECONDARY SIDE EQUATIONS $\ldots \ldots \ldots \ldots \ldots \ldots$

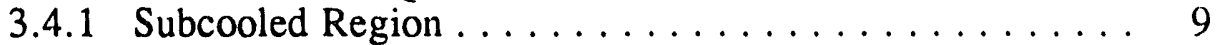

3.4 .2 Nucleate Boiling Region $\ldots \ldots \ldots \ldots \ldots$

3.4.3 Film Boiling Region .................. 18

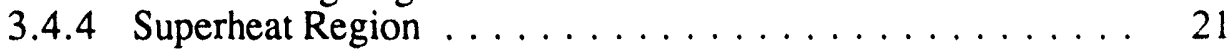

3.5 PRIMARY SIDE EQUATIONS $\ldots \ldots \ldots \ldots \ldots \ldots$

3.6 METAL TEMPERATURE EQUATIONS $\ldots \ldots \ldots \ldots \ldots \ldots$

3.7 MOMENTUM EQUATION . . . . . . . . . . . . . . . . 30

3.8 SUMMARY OF HEAT TRANSFER CORRELATIONS . . . . . . 33

3.8.1 Subcooled Region . . . . . . . . . . . . . . . . . . . 3.35

3.8 .2 Nucleate Boiling Region $\ldots \ldots \ldots \ldots \ldots \ldots$

3.8 .3 Film Boiling Region . . . . . . . . . . . . . . . . 36

3.8 .4 Superheat Region . . . . . . . . . . . . . . . . 37

3.8 .5 Primary Side .................... 37

3.9 THERMODYNAMIC AND PHYSICAL

PROPERTIES OF SODIUM, WATER, AND METAL . . . . . . . 37

3.9 .1 Sodium Properties . . . . . . . . . . . . . . . 37

3.9 .2 Steam/Water Properties . . . . . . . . . . . . . . 38

3.9.3 Physical Properties of the Metal Tubes . . . . . . . . . . . 39

4. RESULTS AND DISCUSSION ... . . . . . . . . . . . . . 4 4

5. CONCLUSIONS $\ldots \ldots \ldots \ldots \ldots \ldots \ldots \ldots$

6. ACKNOWLEDGMENTS ...................... 54

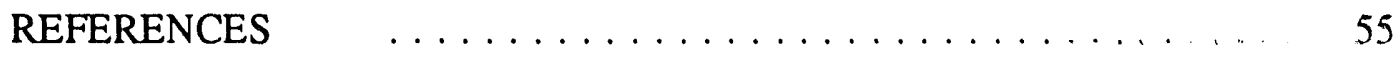

Appendix A. ELEMENTS OF THE A AND B MATRICES . . . . . . . 56 


\section{LIST OF FIGURES}

Figure

Page

1. Once-through, helical-coil steam generator of the

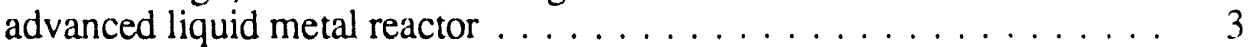

2. Model diagram of the steam generator . . . . . . . . . . . . . 5

3. Schematic diagram of control volume used for the derivation of the conservation equations . . . . . . . . . . . . . . 6

4. Schematic diagram of the nucleate boiling region . . . . . . . . . 11

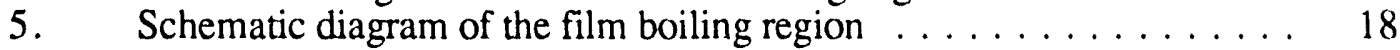

$6 \quad$ Metal temperature nodes ................... 28

7. Inlet and outlet sodium temperatures and the steam outlet temperature following a $10 \%$ increase in inlet sodium temperature transient . . . . . . . . . . . . . . . . . 42

8. Lengths of the subcooled, nucleate boiling, film boiling and superheat regions during the $10 \%$ increase in inlet sodium temperature transient $\ldots \ldots \ldots \ldots \ldots \ldots \ldots$

9. Inlet feedwater pressure during the $10 \%$ increase in inlet sodium temperature transient $\ldots \ldots \ldots \ldots \ldots \ldots \ldots$

10. Rate of steam flow out of the steam generator during the $10 \%$ increase in inlet sodium temperature transient $\ldots \ldots \ldots \ldots$

11. Primary coolant flow rate during the $10 \%$ increase in primary coolant flow rate transient . . . . . . . . . . . . . . . .

12. Lengths of the subcooled, nucleate boiling, film boiling and superheat regions during the $10 \%$ increase in primary coolant flow rate transient $\ldots \ldots \ldots \ldots \ldots \ldots \ldots$

13. Inlet feedwater pressure during the $10 \%$ increase in primary coolant flow rate transient $\ldots \ldots \ldots \ldots \ldots \ldots \ldots \ldots$

14. Steam flow rate during the $10 \%$ increase in primary coolant flow rate transient $\ldots \ldots \ldots \ldots \ldots \ldots \ldots \ldots$

15. Steam flow rate during the $10 \%$ increase in feedwater

flow rate transient . . . . . . . . . . . . . . . . . . . . . .

16. Lengths of the subcooled, nucleate boiling, film boiling and superheated region during the $10 \%$ increase in feedwater flow rate transient

17. Temperature of the outgoing steam and outgoing sodium during the $10 \%$ increase in feedwater flow rate transient . . . . . . . .

18. Feedwater inlet pressure during the $10 \%$ increase in feedwater flow rate transient $\ldots \ldots \ldots \ldots \ldots \ldots$

19. Feedwater inlet pressure and steam outlet pressure during the $10 \%$ increase in outlet steam pressure transient . . . . . . . . .

20. Lengths of the subcooled, nucleate boiling, film boiling and superheat region during the $10 \%$ increase in outlet steam pressure transient $\ldots \ldots \ldots \ldots \ldots \ldots \ldots$

21. Steam flow rate during the $10 \%$ increase in outlet steam pressure transient $\ldots \ldots \ldots \ldots \ldots \ldots \ldots \ldots$

22. Feedwater and steam flow rates during the $80 \%$ decrease in feedwater flow rate transient $\ldots \ldots \ldots \ldots \ldots \ldots$ 


\section{LIST OF FIGURES}

Figure Page

23. Outgoing sodium and steam temperatures during the $80 \%$ decrease in feedwater flow rate transient . . . . . . . . . . . . . . . . . .

24. Lengths of the subcooled, nucleate boiling, film boiling and superheat regions during the $80 \%$ decrease in feedwater

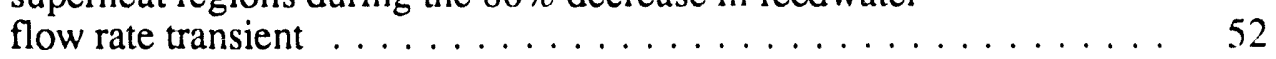

25. Primary and secondary heat transfer rates during the $80 \%$ decrease in feedwater flow rate transient $\ldots \ldots \ldots \ldots \ldots \ldots \ldots \ldots$ 


\begin{abstract}
A dynamic model of a once-through, helical-coil steam generator is presented. The model simulates the advanced liquid metal reactor superheated cycle steam generator with a four-region, moving-boundary, drift-flux flow model. The model is described by a set of nonlinear differential equations derived from the fundamental equations of conservation of mass, energy, and momentum. Sample results of steady-state and transient calculations are presented.
\end{abstract}




\section{INTRODUCTION}

Steam generators in a nuclear power plant provide cooling of the reactor and produce steam to drive the turbine. Characterizations of the thermal-hydraulic transients of the steam generator are essential in the study of the overall nuclear power plant performance as well as for the design of its appropriate control systems. The prediction of the steam generator behavior under load transients requires the use of nonlinear dynamic models of the steam generator.

The steam generator model presented in this report consists of subcooled, nucleate boiling, film boiling, and superhoated regions and uses the moving boundary modeling approach. The basic model equations were derived from the fundamental equations of conservation of mass, energy, and momentum by using control volumes.

The model simulates the steady-state and transient conditions of the once-through steam generator of the advanced liquid metal reactor (ALMR) ${ }^{1,2}$ This steam generator has a helical-coil arrangement and is heated by sodium. It is designed to produce superheated steam. The model can be used as a stand-alone system or as a component of a large-scale nuclear power plant simulator.

The numerical results for the transient response of selected system variables were obtained by simulating the model in the Advanced Continuous Simulation Language $(\mathrm{ACSL}){ }^{3}{ }^{3}$ The model is also implemented in the Generalized Object-Oriented Simulation Environment (GOOSE). ${ }^{4}$

The remainder of this report comprises five sections. Section 2 gives a brief description of the once-through, helical-coil steam generator, and Sect. 3 outlines the mathematical formulation of the model. In Sect. 4, results are given for typical transients, and Sect. 5 contains the closing remarks. 


\section{STEAM GENERATOR DESCRIPTION}

The current superheat design of the Department of Energy's ALMR uses a oncethrough, helical-coil, steam generator. It is a vertical, sodium-to-water counterflow shelland-tube heat exchanger. In each of the three power blocks of the ALMR are three steam generators that operate in parallel and share common feedwater and steam headers. The steam generator exchanges heat from the intermediate heat transport system (IHTS) to the steam generator system and supplies superheated steam to the turbine.

Figure 1 shows the steam generator design to be modeled. The system boundaries are formed by the inlet and outlet nozzles of the liquid sodium on the primary side and the feedwater inlet and steam outlet on the secondary side. The hot secondary sodium coolant coming from the hot leg of the IHTS enters the top of the steam generator and flows downward in the shell side and leaves the steam generator at the bottom. Subcooled feedwater from tiie feedwater header enters the steam generator at the bottom through four feedwater nozzles. The water gains heat from the hot sodium as it flows upward inside the helical tubes. Once it reaches saturation temperature, the water continues upward through a nucleate boiling region, a film boiling region, and a superheat region in a single pass upward through the steam generator. Typical performance parameters and physical characteristics of the steam generator are represented in reference 2 . 


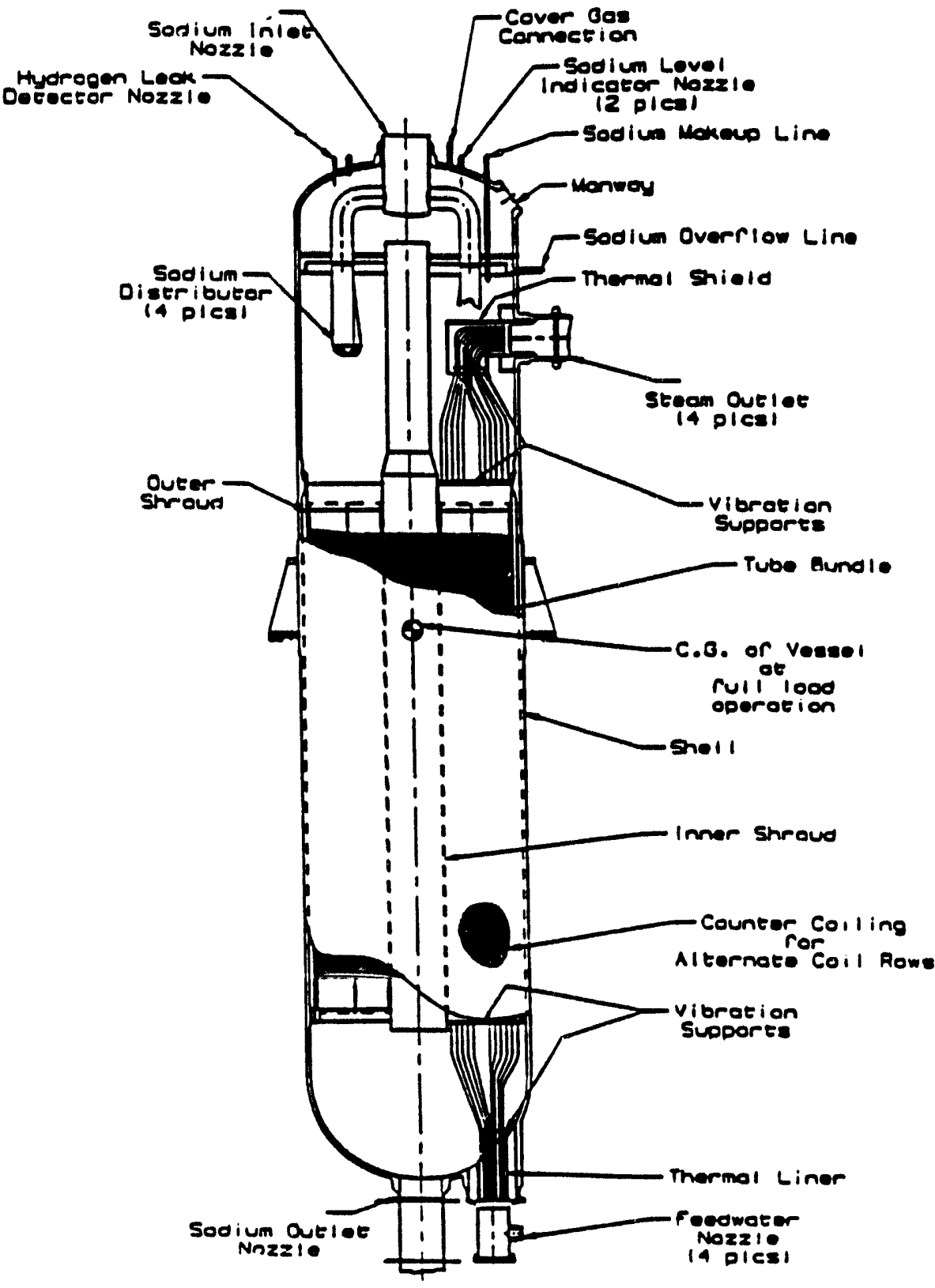

Fig. 1. Once-through, helical-coil steam generator of the advanced liquid metal reactor. Source: C. R. Kakarala and C. E. Boardman, "Advanced Liquid Metal Reactor Helical Coil Steam Generator," Thermal Hydraulics of Advanced Heat Exchangers, NE. Vol. 5, The American Society of Mechanical Engineers. 


\section{MATHEMATICAL FORMULATION OF THE MODEL}

This section deals with the development of the mathematical model of the steam generator used in the nuclear steam supply system of the advanced liquid metal reactor. The general assumptions preceding the mathematical modeling of the steam generator are summarized. The conservation equations, heat transfer and hydraulic correlations, and the equations of state are also discussed.

Figure 2 depicts model nodes and variable names for the steam generator. A typical tube is partitioned into four regions according to the state of the steam/water mixture. They are the subcooled region, nucleate boiling region, film boiling region, and superheat region. The location of the boundary of each region is denoted as follows: $L=L$ is where nucleate boiling starts, $\mathrm{L}=\mathrm{L}_{2}$ is where film boiling begins, and $\mathrm{L}=\mathrm{L}_{3}$ is where film boiling ends. The locations of these boundaries are with respect to the entrance of the tube. For the primary sodium, the energy and mass equations are described. For the tube metal nodes, the energy equations are described.

\subsection{ASSUMPTIONS}

To develop a mathematical model for a complex system such as a steam generator, several fundamental assumptions have to be made.

1. The dynamic behavior of the multitube steam generator is simulated by a single characteristic tube, which is used to represent the behavior of the entire tube bank.

2. The dynamic behavior is one dimensional in the direction of the main flow. The effects of the secondary flow in the radial direction of the helical coil are taken into account by applying correction factors to heat transfer and pressure drop calculations.

3. The heat transfer along the axial direction is neglected whether in the vapor or liquid phase.

4. The dynamics of the steam generator can be adequately described by four moving boundary regions. The length of each region is defined by the mode of heat transfer taking place in that region.

5. Fluid properties over any cross section are uniform.

6. Primary sodium is treated as an incompressible fluid.

7. The mean densities in the boiling regions are determined by using the ZuberFindlay drift-flux correlation. 5

8. Thermodynamic equilibrium between liquid and steam phases is assumed in all boiling regions. Subcooled boiling is neglected.

9. All four water side regions are assumed to be at the same pressure.

10. The relative velocity between the phases in the two-phase regions is characterized by an algebraic drift flux equation.

11. There is no influence on a given tube from its neighboring tubes. 


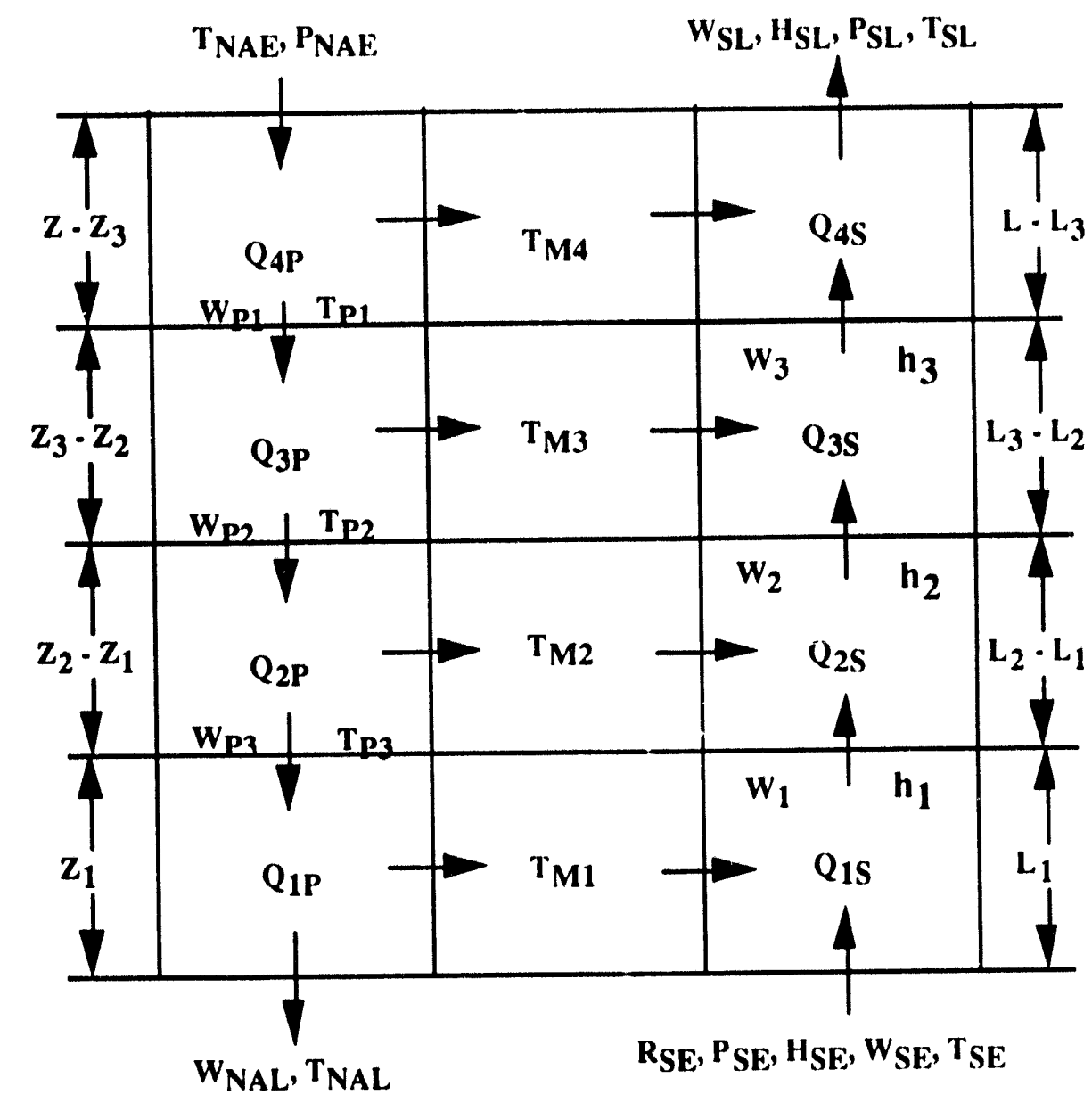

Fig. 2. Model diagram of the steam generator $\left(h=\right.$ enthalpy, $H_{S E}=$ enthalpy of the incoming feedwater, $\mathrm{H}_{S L}=$ enthalpy of the outgoing steam, $\mathrm{L}=$ secondary node length, $\mathrm{P}_{\mathrm{SE}}=$ pressure of the incoming feedwater, $\mathrm{P}_{\mathrm{SL}}=$ pressure of the outgoing steam, $\mathrm{Q}_{\mathrm{P}}=$ primary node heat rate, $\mathrm{Q}_{\mathrm{S}}=$ secondary node heat rate, $\mathrm{R}_{\mathrm{SE}}=$ density of the incoming feedwater, $\mathrm{T}_{\mathrm{M}}=$ metal temperature, $\mathrm{T}_{\mathrm{NAL}}=$ temperature of the outgoing sodium, $\mathrm{T}_{\mathrm{P}}=$ primary temperature, $\mathrm{T}_{\mathrm{SE}}=$ temperature of the incoming feedwater, $\mathrm{T}_{\mathrm{SL}}=$ temperature of the outgoing steam, $\mathrm{W}=$ secondary flow rate, $\mathrm{W}_{\mathrm{NAL}}=$ outgoing sodium flow rate, $\mathrm{W}_{\mathrm{P}}=$ primary flow rate, $\mathrm{W}_{\mathrm{SL}}=$ flow ate of the outgoing steam, $Z$ = primary node length). 


\subsection{MODEL LIMITATIONS}

1. Reverse flows in the primary and secondary sides are not permitted.

2. All regions have to be present.

3. Primary flow must be single phase.

4. Feedwater flow must be single phase.

\subsection{GENERAL CONSERVATION OF MASS AND ENFRGY EQUATIONS}

For a moving-boundary, lumped-parameter formulation, the energy and mass conservation equations are derived in relation to the control volume shown in Fig. 3 . The flow in and out are defined with respect to the moving boundary rather than with the fixed frame of reference.

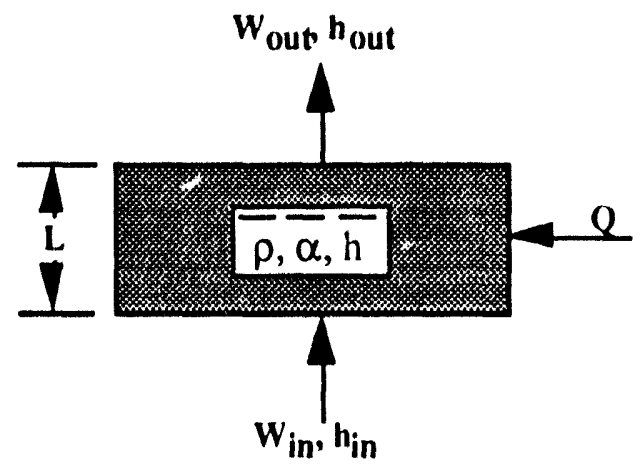

Fig. 3. Schematic diagram of control volume used for the derivation of the conservation equations.

The thermodynamic properties within the control volume are assumed to vary with $\mathrm{L}$ along the length of the node. However, at a fixed value of $\mathrm{L}$, the thermodynamic properties are assumed to be constant across the cross-sectional area of the control volume.

\subsubsection{Conservation of Energy}

Neglecting kinetic and potential energies and assuming no shaft work and no internal heat generation, the conservation of energy for the control volume shown above is

$$
\frac{d \overline{\rho u} V}{d t}=W_{\text {in }} h_{\text {in }}-W_{\text {out }} h_{\text {out }}+Q-P \frac{d V}{d t}
$$


The left-hand side of the energy balance equation represents the rate of change of the average specific internal energy stored in the control volume. The right-hand side represents the sum of the convective heat transfer, the net enthalpy addition due to the flow and the work performed by the control volume boundaries.

Equation (1) is converted from internal energy to enthalpy by using the relation

$$
\overline{\mathrm{u}}=\overline{\mathrm{h}}-\mathrm{P} \overline{\mathrm{v}} \text {. }
$$

Substituting into Eq. (1) yields

$$
\frac{d \bar{\rho}(\bar{h}-P \bar{v}) V}{d t}=W_{\text {in }} h_{\text {in }}-W_{\text {out }} h_{\text {out }}+Q-P \frac{d V}{d t} .
$$

Expanding the derivative provides the following form of the energy equation in terms of enthalpy

$$
\overline{\rho h} \frac{d V}{d t}-V \frac{d \overline{\rho h}}{d t}-V \frac{d P}{d t}=W_{\text {in }} h_{\text {in }}-W_{\text {out }} h_{\text {out }}+Q \text {, }
$$

where the barred quantities represent the averages of these quantities over the control volume and

$$
\begin{aligned}
& \mathrm{h}_{\text {in }}=\text { enthalpy in, } \\
& \mathrm{h}_{\text {out }}=\text { enthalpy out, } \\
& \mathrm{W}_{\text {in }}=\text { flow in, } \\
& \mathrm{W}_{\text {out }}=\text { flow out, } \\
& \mathrm{P} \quad=\text { pressure, } \\
& \mathrm{Q} \quad=\text { heat, } \\
& \mathrm{V} \quad=\text { volume of the control volume, } \\
& \rho \quad=\text { density. }
\end{aligned}
$$

\subsubsection{Conservation of Mass}

The conservation of mass in a region is written in terms of the average density of the region,

$$
\frac{d \bar{\rho} V}{d t}=W_{\text {in }}-W_{\text {out }} \text {. }
$$

Expanding the derivative gives

$$
\bar{\rho} \frac{d V}{d t}+V \frac{d \bar{\rho}}{d t}=W_{\text {in }}-W_{\text {out }},
$$


with the volume of the region expressed as

$$
\mathrm{V}=\mathrm{AL}
$$

where

$A=$ cross sectional area of the flow,

$\mathrm{L}=$ length of the region.

The mathematical model of the steam generator is generally based on the conservation equations [Eqs. (4) and (6)] and the assumptions listed above. The equations resulting from the application of these equations to the system regions coupled with empirical correlations for heat transfer, pressure drops, single- and two-phase flow properties complete the description of the mathematical model presented in this report.

\subsection{SECONDARY SIDE EQUATIONS}

A typical helical-coil tube is divided into four regions: subcooled, nucleate boiling, film boiling, and superheated. Because the boundary between any two regions is a function of load and thermodynamic properties, the length of a region is treated as a variable in the dynamic equations. Each of the four regions must always be present during a transient.

Void distribution in the two-phase regions is modeled by a quasi-steady state integral average of the Zuber-Findlay drift-flux reiationship. Each region is characterized by heat and hydrodynamic correlations. The conditions for separating one region from another are listed below.

1. The subcooled region extends from the inlet of the steam side of the steam generator to the point at which the bulk enthalpy of the region is equal to the liquid saturation enthalpy.

2. The nucleate boiling region extends from the exit from the subcooled region to the point where the steam quality reaches the critical quality for departure from nucleate boiling $\left(\mathrm{X}_{\mathrm{DNB}}\right)$. The condition for departure from nucleate boiling for water in the helical coil is determined from the empirical equation, ${ }^{6}$

$$
X_{D N B}=\frac{18.85 \rho_{f}}{\rho_{B}\left(h_{f}-h_{g}\right) \sqrt{G \times 10^{-6}}}
$$

where

$$
\begin{aligned}
& h_{f}=\text { liquid enthalpy, } \\
& h_{g}=\text { steam enthalpy, } \\
& \rho_{f}=\text { liquid density } \\
& \rho_{g}=\text { vapor density. }
\end{aligned}
$$


The mass flux $G$ in the above equation is calculated in terms of the feedwater flow $W_{S E}$ and the secondary cross-sectional area of the secondary flow $\mathrm{A}_{\mathrm{S}}$ by using

$$
\mathrm{G}=\frac{\mathrm{W}_{\mathrm{SE}}}{\mathrm{A}_{\mathrm{S}}} .
$$

3. The film boiling region extends from the exit from the nucleate boiling region to the point at which the bulk enthalpy of the region is equal to the fluid saturation steam.

4. The superheat region defines the remainder of the steam generator.

The conservation equations for two-phase flow are based on the assumption of algebraic drift flux with thermal equilibrium between the phases. The continuity and energy equations for the secondary coolant in each of the four regions are derived in the following sections.

\subsubsection{Subcooled Region} form

Application of the conservation of energy principle to the subcooled region takes the

$$
\frac{d \overline{\rho_{1} u_{1}} V_{1}}{d t}=W_{S E} h_{S E}-W_{1} h_{1}-P_{1} \frac{d V_{1}}{d t}+Q_{S C}
$$

where

$\mathrm{h}_{\mathrm{SE}}=$ enthalpy of the entering feedwater,

$\mathrm{Q}_{\mathrm{SC}}=$ heat transferred into the subcooled region,

and in terms of the average enthalpy of the region, Eq. (10) becomes

$$
\frac{\overline{d \rho_{1} h_{1}} V_{1}}{d t}=W_{S E} h_{S E}-W_{1} h_{1}+V_{1} \frac{d P_{1}}{d t}+Q_{S C}
$$

The conservation of mass equation is

$$
\frac{\mathrm{d} \bar{\rho}_{1} V_{1}}{\mathrm{dt}}=\mathrm{W}_{\mathrm{SE}}-\mathrm{W}_{1}
$$

It is assumed that all of the heat conducted into the subcooled region is absorbed by the feedwater as it is heated to saturation temperature and is represented by the expression

$$
\mathrm{Q}_{\mathrm{SC}}=\mathrm{W}_{1}\left(\mathrm{~h}_{\mathrm{f}}-\overline{\mathrm{h}}_{1}\right) \text {. }
$$


From Eq. (13), the outgoing flow rate is

$$
W_{1}=\frac{Q_{s c}}{\left(h_{f}-h_{1}\right)}
$$

where $h_{f}=h_{1}$ is the enthalpy of the water at the boundary of the subcooled/nucleate boiling regions. Substituting Eq. (14) into Eq. (12) and expanding the derivative results in

$$
\overline{\rho_{1}} \frac{d V_{1}}{d t}+V_{1} \frac{d \bar{\rho}_{1}}{d t}=W_{S E}-\frac{Q_{S C}}{\left(h_{1}-\bar{h}_{1}\right)}
$$

Substitution of Eq. (14) into Eq. (11) and expanding the derivative, the energy equation becomes

$$
V_{1} \frac{d \overline{\rho_{1} h_{1}}}{d t}+\overline{\rho_{1} h_{1}} \frac{d V_{1}}{d t}-V_{1} \frac{d P_{1}}{d t}=W_{S E} h_{S E}-\frac{Q_{S C} \overline{h_{1}}}{\left(h_{1}-\overline{h_{1}}\right)}
$$

Multiplying Eq. (15) by the average enthalpy of the subcooled region $h_{1}$ and subtracting the result from Eq. (16) gives the energy equation

$$
V_{1} \bar{\rho}_{1} \frac{d \bar{h}_{1}}{d t}-V_{1} \frac{d P_{1}}{d t}=W_{S E}\left(h_{S E}-\overline{h_{1}}\right)
$$

The average density of the subcooled region is assumed to be a function of the enthalpy and pressure of the region,

$$
\overline{\rho_{1}}=f(h, P)
$$

taking the partial derivative of the average density of the subcooled region results in

$$
\frac{d \bar{\rho}_{1}}{d t}=\frac{\partial \bar{\rho}_{1}}{\partial \mathrm{h}} \frac{d \bar{h}_{1}}{d t}+\frac{\partial \bar{\rho}_{1}}{\partial \mathrm{P}} \frac{d P_{1}}{d t}
$$

Substitution of Eq. (19) into Eq. (15) yields

$$
V_{1} \frac{\partial \bar{\rho}_{1}}{\partial \mathrm{h}} \frac{\mathrm{d} \bar{h}_{1}}{\mathrm{dt}}+\mathrm{V}_{1} \frac{\partial{\overline{\rho_{1}}}_{1}}{\partial \mathrm{P}} \frac{\mathrm{P}}{\mathrm{dt}}+\overline{\rho_{1}} \mathrm{~A}_{\mathrm{s}} \frac{\mathrm{dL}}{\mathrm{dt}}=\mathrm{W}_{\mathrm{SE}}-\frac{\mathrm{Q}_{\mathrm{sC}}}{\left(\mathrm{h}_{1}-\overline{\mathrm{h}}_{1}\right)}
$$


where the volume of the subcooled region is

$$
\mathrm{V}_{1}=\mathrm{A}_{s} \mathrm{~L}_{1}
$$

and its time derivative is

$$
\frac{\mathrm{dV}_{1}}{\mathrm{dt}}=\mathrm{A}_{\mathrm{s}} \frac{\mathrm{dL}}{\mathrm{dt}}
$$

The average density of the subcooled region is expressed as an average of the inlet and outlet densities,

$$
\overline{\rho_{1}}=\frac{\left[\rho_{\text {SE }}+\rho_{\mathrm{f}}\left(P_{1}\right)\right]}{2}
$$

Similarly, the average enthalpy of the region is assumed to be an average of the inlet and outlet enthalpies,

where

$$
\overline{h_{1}}=\frac{\left(h_{S E}+h_{1}\right)}{2}
$$

$$
h_{1}=h_{f}\left(P_{1}\right)
$$

\subsubsection{Nucleate Boiling Region}

Because the size and density of the nucleate boiling region (Fig. 4) experience changes during transients, the energy and mass balance equations are necessary for the description of the dynamics of the region.

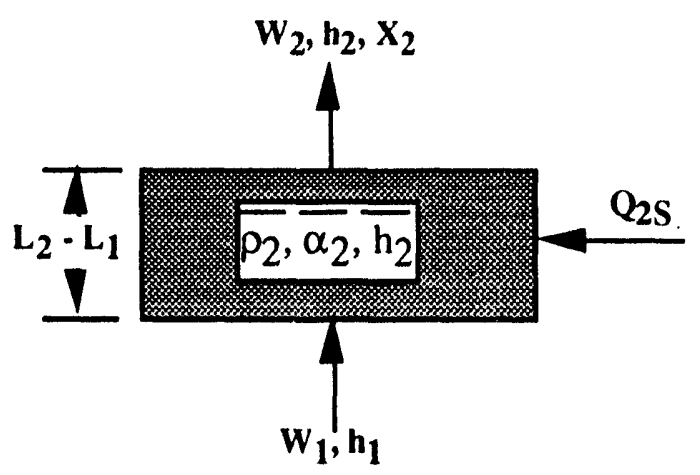

Fig. 4. Schematic diagram of the nucleate boiling region. 
The two phases are assumed to be in thermal equilibrium. Thus, the energy balance is represented by a single equation that applies to the average specific internal energy of the mixture,

$$
\frac{d \overline{\rho_{2} u_{2}} V_{2}}{d t}=W_{1} h_{1}-W_{2} h_{2}-P_{2} \frac{d V_{2}}{d t}+Q_{2 s}
$$

Expressing Eq. (26) in terms of the average enthalpy of the mixture,

$$
\frac{d \overline{\rho_{2} h_{2}} V_{2}}{d t}-V_{2} \frac{d P_{2}}{d t}=W_{1} h_{1}-W_{2} h_{2}+Q_{2 s}
$$

Expanding the derivative gives

$$
V_{2} \frac{d \overline{\rho_{2} h_{2}}}{d t}+\overline{\rho_{2} h_{2}} \frac{d V_{2}}{d t}-V_{2} \frac{d P_{2}}{d t}=W_{1} h_{1}-W_{2} h_{2}+Q_{2 s} .
$$

The two-phase mass equation is

$$
\frac{d \overline{\rho_{2}} V_{2}}{d t}=W_{1}-W_{2}
$$

Expanding the derivative gives

$$
V_{2} \frac{d \bar{\rho}_{2}}{d t}+\overline{\rho_{2}} \frac{d V_{2}}{d t}=W_{1}-W_{2}
$$

where the two-phase density $\rho_{2}$ is a weighted average of the liquid and vapor saturation densities and is represented by

$$
\overline{\rho_{2}}=\overline{\alpha_{2}}\left(\rho_{8}-\rho_{f}\right)+\rho_{f} .
$$

Taking the total time derivative of the average density gives

$$
\frac{d \bar{\rho}_{2}}{d t}=\left(\rho_{B}-\rho_{f}\right) \frac{d \bar{\alpha}_{2}}{d t}+\left[\left(1-\overline{\alpha_{2}}\right) \frac{\partial \rho_{f}}{\partial P}+\overline{\alpha_{2}} \frac{\partial \rho_{B}}{\partial P}\right] \frac{d P_{2}}{d t}
$$


At an elevation $\mathrm{L}$ inside the nucleate boiling region, the product of density and enthalpy is

$$
\rho(L) h(L)=\alpha(L)\left(\rho_{g} h_{g}-\rho_{f} h_{f}\right)+\rho_{f} h_{f} .
$$

Because the saturation properties $\rho_{f}, \rho_{g}, h_{f}$, and $h_{g}$ are constant over the region, the average of $\rho h$ over $L$ from top to bottom of the nucleate boiling region can be expressed in terms of the average void fraction,

$$
\overline{\rho_{2} h_{2}}=\overline{\alpha_{2}}\left(\rho_{8} h_{8}-\rho_{f} h_{f}\right)+\rho_{f} h_{f},
$$

where the enthalpy at nucleate/film boiling boundary is expressed in terms of the steam quality $\mathrm{X}$ as

and

$$
h_{2}=(1-X) h_{f}+X h_{g}
$$

$$
\overline{h_{2}}=\frac{\overline{\rho_{2} h_{2}}}{\rho_{2}}
$$

The Zuber-Findlay Drift Correlation, an algebraic correlation between the flow quality and the void fraction, is used to determine the average quantities at any level. The average void fraction is represented by

$$
\alpha(L)=\frac{X(L)}{C_{o}\left[\left(1-\frac{\rho_{g}}{\rho_{f}}\right) X(L)+\frac{\rho_{g}}{\rho_{f}}\right]+\frac{\rho_{g} V_{g}}{G}}=\frac{X(L)}{a+b X(L)},
$$

where

and

$$
\begin{aligned}
& a=\frac{C_{0} \rho_{B}}{\rho_{f}}+\frac{\rho_{B} V_{B}}{G}, \\
& b=C_{0}-\frac{C_{0} \rho_{g}}{\rho_{f}},
\end{aligned}
$$

$$
\begin{aligned}
& \mathrm{C}_{\mathrm{o}}=\text { distribution parameter } \\
& \mathrm{V}_{\mathrm{g}}=\text { drift velocity. }
\end{aligned}
$$


Both the distribution parameter and the drift velocity are treated as constants throughout the region. The volume weighted average $\alpha$ is

$$
\overline{\alpha_{2}}=\frac{\int_{L_{1}}^{L_{2}} \alpha(L) d L}{L_{2}-L_{1}} .
$$

The flow quality of the region $X$ is assumed a value of zero at $L=L_{1}$ and to a value of $\mathrm{X}_{2}$ at $\mathrm{L}=\mathrm{L}_{2}$. By assuming uniform heat flux, a relationship between flow quality and level can be obtained:

$$
X=\frac{X_{2}}{X_{2}-X_{1}}\left(L-L_{2}\right)
$$

and

$$
\mathrm{dX}=\frac{\mathrm{L}_{2}}{\mathrm{~L}_{2}-\mathrm{L}_{1}} \mathrm{dL}
$$

Substitution of Eqs. (37) and (42) into Eq. (40) gives an integral relation in terms of $X$ alone:

$$
\overline{\alpha_{2}}=\frac{1}{\Delta X} \int_{x_{1}}^{x_{2}} \frac{X}{a+b X} d X
$$

where $X_{1}=0$ and $\Delta X=X_{2}=X_{D N B}$. Taking the integral of Eq. (43) results in

$$
\overline{\alpha_{2}}=\frac{1}{b}+\frac{a}{b^{2} X_{D N B}} \ln \left(\frac{a+b X_{D N B}}{a}\right) .
$$

The algebraic relationship for average void fraction $\alpha_{2}$ is a function of pressure, mixture quality, and mass flux:

$$
\overline{\alpha_{2}}=f(X, P, G) \text {. }
$$

The total time derivative of the void fraction is written by chain rule as

$$
\frac{\mathrm{d} \bar{\alpha}_{2}}{\mathrm{dt}}=\frac{\partial \overline{\alpha_{2}}}{\partial \mathrm{P}} \frac{\mathrm{dP}}{\mathrm{dt}}+\frac{\partial \overline{\alpha_{2}}}{\partial \mathrm{X}} \frac{\mathrm{dX}}{\mathrm{dt}}+\frac{\partial \overline{\alpha_{2}}}{\partial \mathrm{G}} \frac{\mathrm{dG}}{\mathrm{dt}}
$$


Taking the partial derivatives of $\alpha_{2}$,

$$
\begin{gathered}
\frac{\partial \bar{\alpha}_{2}}{\partial X}=-\left[\frac{a}{b X(a+b X)}+\frac{a}{b^{2} X^{2}} \ln \left(\frac{a}{a+b X}\right)\right] \\
\frac{\partial \overline{\alpha_{2}}}{\partial G}=\frac{1}{b X(a+b X)}\left(X \frac{\partial a}{\partial G}-a \frac{\partial X}{\partial G}\right)+\frac{1}{b^{2} X^{2}}\left(X \frac{\partial a}{\partial G}-a \frac{\partial X}{\partial G}\right) \ln \left(\frac{a}{a+b X}\right) \\
\frac{\partial \bar{\alpha}_{2}}{\partial P}=-\frac{\frac{\partial b}{\partial P}}{b^{2}}+\frac{1}{b^{2} X(a+b X)}\left(b X \frac{\partial a}{\partial P}-a b \frac{\partial X}{\partial P}-a X \frac{\partial b}{\partial P}\right) \\
+\frac{1}{b^{2} X^{2}}\left[b^{2} X \frac{\partial a}{\partial P}-a\left(b^{2} \frac{\partial X}{\partial P}+2 b X \frac{\partial b}{\partial P}\right)\right] \ln \left(\frac{a}{a+b X}\right)
\end{gathered}
$$

The departure from nucleate boiling is represented by the algebraic relation

$$
X_{D N B}=\frac{18.85 \rho_{f}}{\rho_{B}\left(h_{f}-h_{g}\right) \sqrt{G \times 10^{-6}}}
$$

To avoid computational difficulties for small flow quality or small mass flux, the arguments of the average void fraction are limited to $0.001<\mathrm{X}<0.99$ and $\mathrm{G}>0.25 \mathrm{ft} / \mathrm{s}$. The flow quality $X$ is assumed to be dependent on pressure and mass flux

$$
X=f(P, G) .
$$

The total derivative of the Eq. (51) is

$$
\frac{d X}{d t}=\frac{\partial X}{\partial P} \frac{d P}{d t}+\frac{\partial X}{\partial G} \frac{d G}{d t}
$$

Substitution of Eq. (52) into Eq. (46) reduces the total derivative of the void fraction to dependence on two state derivatives:

$$
\frac{\mathrm{d} \bar{\alpha}_{2}}{\mathrm{dt}}=\left(\frac{\partial \overline{\alpha_{2}}}{\partial \mathrm{P}}+\frac{\partial \overline{\alpha_{2}}}{\partial \mathrm{X}} \frac{\partial \mathrm{X}}{\partial \mathrm{P}}\right) \frac{\mathrm{dP}}{\mathrm{dt}}+\left(\frac{\partial \overline{\alpha_{2}}}{\partial \mathrm{G}}+\frac{\partial \overline{\alpha_{2}}}{\partial \mathrm{X}} \frac{\partial \mathrm{X}}{\partial \mathrm{G}}\right) \frac{\mathrm{dG}}{\mathrm{dt}}
$$


The partial derivatives of $X_{D N B}$ with respect to pressure and mass flux are

$$
\begin{gathered}
\frac{\partial X_{D N B}}{\partial G}=-\frac{9.425 \times 10^{-6}}{\frac{h_{f_{B}} \rho_{8}}{\rho_{f}}\left[G \times 10^{-6}\right]^{\frac{3}{2}}}, \\
\frac{\partial X_{D N B}}{\partial P}=\frac{18.85}{\sqrt{G \times 10^{-6}}}\left[\frac{h_{f_{B}} \rho_{8}\left(\frac{\partial \rho_{f}}{\partial P}\right)-\rho_{f} \rho_{8}\left(\frac{\partial h_{B}}{\partial P}-\frac{\partial h_{f}}{\partial P}\right)-h_{f_{g}} \rho_{f}\left(\frac{\partial \rho_{8}}{\partial P}\right)}{\left[h_{f_{8}} \rho_{B}\right]^{2}}\right],
\end{gathered}
$$

where

$$
\begin{aligned}
& \frac{\partial a}{\partial P}=\frac{C_{0}}{\rho_{f}} \frac{\partial \rho_{8}}{\partial P}-\frac{C_{0} \rho_{8}}{\rho_{f}^{2}} \frac{\partial \rho_{f}}{\partial P}+\frac{V}{G} \frac{\partial \rho_{g}}{\partial P}, \\
& \frac{\partial a}{\partial G}=-\frac{\rho_{8} V_{8}}{G^{2}}, \\
& \frac{\partial b}{\partial P}=-\frac{C_{0}}{\rho_{f}} \frac{\partial \rho_{8}}{\partial P}+\frac{C_{0} \rho_{g}}{\rho_{f}^{2}} \frac{\partial \rho_{f}}{\partial P} .
\end{aligned}
$$

The volume of the nucleate boiling region is expressed as

$$
\mathrm{V}_{2}=A_{s}\left(L_{2}-L_{1}\right)
$$

and its time derivative is

$$
\frac{\mathrm{dV}_{2}}{\mathrm{dt}}=\mathrm{A}_{\mathrm{s}}\left(\frac{\mathrm{dl}_{2}}{\mathrm{dt}}-\frac{\mathrm{dl}_{1}}{\mathrm{dt}}\right) .
$$

Substitution of Eq. (53) into Eq. (32) results in

$$
\begin{aligned}
\frac{d \overline{\rho_{2}}}{\mathrm{dt}} & =\left[\overline{\alpha_{2}} \frac{\partial \rho_{\mathrm{g}}}{\partial \mathrm{P}}+\left(1-\overline{\alpha_{2}}\right) \frac{\partial \rho_{\mathrm{f}}}{\partial \mathrm{P}}+\left(\rho_{\mathrm{g}}-\rho_{\mathrm{f}}\right)\left(\frac{\partial \overline{\alpha_{2}}}{\partial \mathrm{P}}+\frac{\partial \overline{\alpha_{2}}}{\partial \mathrm{X}} \frac{\partial \mathrm{X}}{\partial \mathrm{P}}\right)\right] \frac{\mathrm{dP}}{\mathrm{dt}} \\
& +\left[\left(\rho_{\mathrm{g}}-\rho_{\mathrm{f}}\right)\left(\frac{\partial \overline{\alpha_{2}}}{\partial \mathrm{G}}+\frac{\partial \overline{\alpha_{2}}}{\partial \mathrm{X}} \frac{\partial \mathrm{X}}{\partial \mathrm{G}}\right)\right] \frac{\mathrm{dG}}{\mathrm{dt}} .
\end{aligned}
$$


Taking the total derivative of Eq. (34) gives

$$
\begin{aligned}
\frac{d \overline{\rho_{2} h_{2}}}{d t} & =\left[\left(1-\overline{\alpha_{2}}\right)\left(\rho_{1} \frac{\partial h_{1}}{\partial P}+h_{f} \frac{\partial \rho_{f}}{\partial P}\right)+\overline{\alpha_{2}}\left(\rho_{8} \frac{\partial h_{8}}{\partial P}+h_{8} \frac{\partial \rho_{8}}{\partial P}\right)\right] \frac{d P}{d t} \\
& +\left(\rho_{8} h_{8}-\rho_{f} h_{t}\right) \frac{d \overline{\alpha_{2}}}{d t} .
\end{aligned}
$$

Substitution of Eq. (53) into Eq.(62) yields

$$
\begin{aligned}
\frac{d \overline{\rho_{2} h_{2}}}{d t} & =\left[\begin{array}{l}
\left.\left(1-\bar{\alpha}_{2}\right)\left(\rho_{f} \frac{\partial h_{f}}{\partial P}+h_{1} \frac{\partial \rho_{1}}{\partial P}\right)+\overline{\alpha_{2}}\left(\rho_{8} \frac{\partial h_{8}}{\partial P}+h_{8} \frac{\partial \rho_{8}}{\partial P}\right)\right] \frac{d P_{2}}{d t} \\
+\left(\rho_{8} h_{8}-\rho_{f} h_{f}\right)\left(\frac{\partial \bar{\alpha}_{2}}{\partial P}+\frac{\partial \alpha_{2}}{\partial X} \frac{\partial X}{\partial P}\right)
\end{array}\right] \\
& +\left(\rho_{8} h_{8}-\rho_{f} h_{f}\right)\left(\frac{\partial \overline{\alpha_{2}}}{\partial G}+\frac{\partial \overline{\alpha_{2}}}{\partial X} \frac{\partial X}{\partial G}\right) \frac{d G}{d t} .
\end{aligned}
$$

Substitution of Eqs. (14), (34), (59), (60), and (62) into Eq. (28) results in

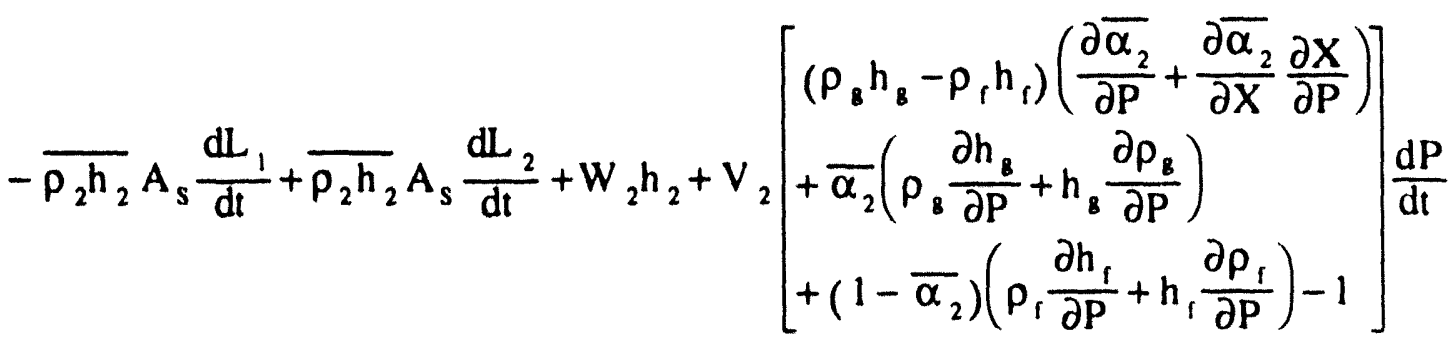

$$
\begin{aligned}
& =Q_{2 s}+\frac{Q_{1 s}}{\left(h_{1}-h_{1}\right)}-V_{2}\left(\rho_{8} h_{8}-\rho_{1} h_{f}\right)\left(\frac{\partial \overline{\alpha_{2}}}{\partial G}+\frac{\partial \overline{\alpha_{2}}}{\partial X} \frac{\partial X}{\partial G}\right) \frac{d G}{d t} .
\end{aligned}
$$


Substitution of Eqs. (14), (31), (59), (60), and (61) into Eq. (30) results in

$$
\begin{aligned}
& -\bar{\rho}_{2} A_{s} \frac{d_{1}}{d t}+\bar{\rho}_{2} A_{s} \frac{d L_{2}}{d t}+W_{2}+V_{2}\left[\begin{array}{c}
\left(\rho_{B}-\rho_{f}\right)\left(\frac{\partial \overline{\alpha_{2}}}{\partial P}+\frac{\partial \overline{\alpha_{2}}}{\partial X} \frac{\partial X}{\partial P}\right) \\
+\overline{\alpha_{2}} \frac{\partial \rho_{B}}{\partial P}+\left(1-\overline{\alpha_{2}}\right) \frac{\partial \rho_{f}}{\partial P}
\end{array}\right] \frac{d P}{d t} \\
& =\frac{Q_{1 s}}{\left(h_{1}-h_{1}\right)}-V_{2}\left(\rho_{B}-\rho_{f}\right)\left(\frac{\partial \bar{\alpha}_{2}}{\partial G}+\frac{\partial \overline{\alpha_{2}}}{\partial X} \frac{\partial X}{\partial G}\right) \frac{d G}{d t},
\end{aligned}
$$

where the time derivative of the mass flux $G$ is evaluated from the momentum equation across the tube

$$
\frac{d G}{d t}=\frac{\frac{d W_{S E}}{d t}}{A_{S}} .
$$

\subsubsection{Film Boiling Region}

The derivation of the conservation of energy and mass equations for the film boiling region (Fig. 5) is similar to that for the nucleate boiling region. Thus, only the main equations are presented in this section.

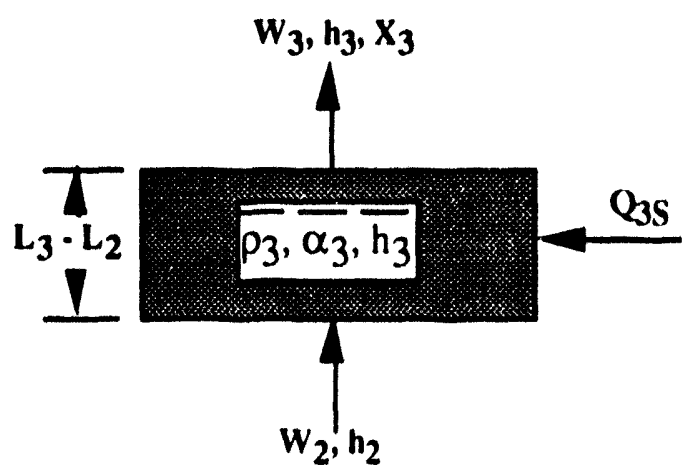

Fig. 5. Schematic diagram of the film boiling region. 
The conservation of energy equation is

$$
V_{3} \frac{d \overline{\rho_{3} h_{3}}}{d t}+\overline{\rho_{3} h_{3}} \frac{d V_{3}}{d t}-V_{3} \frac{d P_{3}}{d t}=W_{2} h_{2}-W_{3} h_{3}+Q_{3 s}
$$

Application of the law of conservation of mass yields

$$
V_{3} \frac{d \overline{\rho_{3}}}{d t}+\overline{\rho_{3}} \frac{d V_{3}}{d t}=W_{2}-W_{3},
$$

where the volume of the region is

$$
V_{3}=A_{s}\left(L_{3}-L_{2}\right)
$$

and its time derivative is

$$
\frac{\mathrm{dV}_{3}}{\mathrm{dt}}=\mathrm{A}_{\mathrm{s}}\left(\frac{\mathrm{dL}_{3}}{\mathrm{dt}}-\frac{\mathrm{dl}_{2}}{\mathrm{dt}}\right) .
$$

The average of $\rho$ over the film boiling region is

$$
\overline{\rho_{3} h_{3}}=\overline{\alpha_{3}}\left(\rho_{8} h_{8}-\rho_{f} h_{f}\right)+\rho_{f} h_{f},
$$

where

and

$$
h_{3}=h_{8}\left(P_{3}\right)
$$

$$
\overline{h_{3}}=\frac{\overline{\rho_{3} h_{3}}}{\rho_{3}} \text {. }
$$

The average density and void fraction of the region are expressed as

$$
\begin{aligned}
& \overline{\rho_{3}}=\overline{\alpha_{3}}\left(\rho_{B}-\rho_{f}\right)+\rho_{f} \\
& \overline{\alpha_{3}}=\frac{1}{b}+\frac{a}{b^{2}(1-X)} \ln \left(\frac{a+b X}{a+b}\right) .
\end{aligned}
$$


The total derivative of the average density and void fraction of the film boiling region are

$$
\begin{aligned}
\frac{\mathrm{d} \bar{\alpha}_{3}}{\mathrm{dt}}=\left(\frac{\partial \bar{\alpha}_{3}}{\partial \mathrm{P}}+\frac{\partial \bar{\alpha}_{3}}{\partial \mathrm{X}} \frac{\partial \mathrm{X}}{\partial \mathrm{P}}\right) \frac{\mathrm{dP}}{\mathrm{dt}}+\left(\frac{\partial \bar{\alpha}_{3}}{\partial \mathrm{G}}+\frac{\partial \overline{\alpha_{3}}}{\partial \mathrm{X}} \frac{\partial \mathrm{X}}{\partial \mathrm{G}}\right) \frac{\mathrm{dG}}{\mathrm{dt}} \\
\frac{\mathrm{d} \bar{\rho}_{3}}{\mathrm{dt}}=\left[\bar{\alpha}_{3} \frac{\partial \rho_{3}}{\partial \mathrm{P}}+\left(1-\bar{\alpha}_{3}\right) \frac{\partial \rho_{\mathrm{f}}}{\partial \mathrm{P}}+\left(\rho_{8}-\rho_{\mathrm{f}}\right)\left(\frac{\partial \bar{\alpha}_{3}}{\partial \mathrm{P}}+\frac{\partial \bar{\alpha}_{3}}{\partial \mathrm{X}} \frac{\partial \mathrm{X}}{\partial \mathrm{P}}\right)\right] \frac{\mathrm{dP}}{\mathrm{dt}} \\
+\left[\left(\rho_{8}-\rho_{\mathrm{t}}\right)\left(\frac{\partial \bar{\alpha}_{3}}{\partial \mathrm{G}}+\frac{\partial \overline{\alpha_{3}}}{\partial \mathrm{X}} \frac{\partial \mathrm{X}}{\partial \mathrm{G}}\right)\right] \frac{\mathrm{d} \underline{\mathrm{G}}}{\mathrm{dt}} .
\end{aligned}
$$

The total derivative of Eq. (71) is

$$
\begin{aligned}
& \frac{d \overline{\rho_{3} h_{3}}}{d t}=\left[\begin{array}{l}
\left(1-\overline{\alpha_{3}}\right)\left(\rho_{t} \frac{\partial h_{1}}{\partial \mathrm{P}}+h_{1} \frac{\partial \rho_{1}}{\partial \mathrm{P}}\right)+\overline{\alpha_{3}}\left(\rho_{8} \frac{\partial h_{8}}{\partial \mathrm{P}}+h_{8} \frac{\partial \rho_{8}}{\partial \mathrm{P}}\right) \\
+\left(\rho_{8} h_{8}-\rho_{\mathrm{f}} \mathrm{h}_{\mathrm{f}}\right)\left(\frac{\partial \overline{\alpha_{3}}}{\partial \mathrm{P}}+\frac{\partial \bar{\alpha}_{3}}{\partial \mathrm{X}} \frac{\partial \mathrm{X}}{\partial \mathrm{P}}\right)
\end{array}\right] \frac{\mathrm{dP}}{\mathrm{dt}} \\
& +\left(\rho_{8} h_{8}-\rho_{f} h_{f}\right)\left(\frac{\partial \overline{\alpha_{3}}}{\partial \mathrm{G}}+\frac{\partial \overline{\alpha_{3}}}{\partial \mathrm{X}} \frac{\partial \mathrm{X}}{\partial \mathrm{G}}\right) \cdot \frac{\mathrm{dG}}{\mathrm{d} !} .
\end{aligned}
$$

The partial derivatives of the region's average fraction with respect to quality, pressure, and mass flux $G$ are

$$
\begin{gathered}
\frac{\partial \overline{\alpha_{3}}}{\partial X}=\frac{a b}{b^{2}(1-X)(a+b X)}+\frac{a b^{2}}{\left[b^{2}(1-X)\right]^{2}} \ln \left(\frac{a+b X}{a+b}\right), \\
\frac{\partial \overline{\alpha_{3}}}{\partial P}=-\frac{\frac{\partial b}{\partial P}}{b^{2}}+\frac{a}{b^{2}(1-X)(a+b X)}\left[b(1-X) \frac{\partial a}{\partial P}+b(a+b) \frac{\partial X}{\partial P}-a(1-X) \frac{\partial b}{\partial P}\right] \\
+\frac{1}{\left[b^{2}(1-X)\right]^{2}}\left\{b^{2}(1-X) \frac{\partial a}{\partial P}+a\left[b^{2} \frac{\partial X}{\partial P}-2 b(1-X) \frac{\partial b}{\partial P}\right]\right\} \ln \left(\frac{a+b X}{a+b}\right),
\end{gathered}
$$




$$
\begin{aligned}
\frac{\partial \bar{\alpha}_{3}}{\partial G} & =\frac{a}{b^{2}(1-X)(a+b X)}\left[\frac{b(a+b) \frac{\partial X}{\partial G}+b(1-X) \frac{\partial a}{\partial G}}{a+b}\right] \\
& +\frac{1}{\left[b^{2}(1-X)\right]^{2}}\left[b^{2}(1-X) \frac{\partial a}{\partial G}+a b^{2} \frac{\partial X}{\partial G}\right] \ln \left(\frac{a+b X}{a+b}\right)
\end{aligned}
$$

Substitution of Eqs. (70), (71), (72), and (78), into Eq. (67) results in the energy equation for the film boiling region:

$$
\begin{aligned}
& -V_{3}\left[\begin{array}{l}
\left(\rho_{g} h_{g}-\rho_{f} h_{f}\right)\left(\frac{\partial \bar{\alpha}_{3}}{\partial P}+\frac{\partial \bar{\alpha}_{3}}{\partial X} \frac{\partial X}{\partial P}\right) \\
+\bar{\alpha}_{3}\left(\rho_{B} \frac{\partial h_{B}}{\partial P}+h_{B} \frac{\partial \rho_{g}}{\partial P}\right) \\
+\left(1-\bar{\alpha}_{3}\right)\left(\rho_{\mathrm{r}} \frac{\partial h_{f}}{\partial P}+h_{f} \frac{\partial \rho_{f}}{\partial P}\right)-1
\end{array}\right] \frac{d P}{d t}+\overline{\rho_{3} h_{3}} A_{s} \frac{d L_{2}}{d t}-\overline{\rho_{3} h_{3}} A_{s} \frac{d_{3}}{d t} \\
& +W_{2} h_{2}-W_{3} h_{3}=-Q_{2 s}+\frac{Q_{1 s}}{\left(h_{1}-h_{1}\right)}+V_{3}\left(\rho_{g} h_{g}-\rho_{f} h_{f}\right)\left(\frac{\partial \overline{\alpha_{3}}}{\partial G}+\frac{\partial \overline{\alpha_{3}}}{\partial X} \frac{\partial X}{\partial G}\right) \frac{d G}{d t} \text {. }
\end{aligned}
$$

Substitution of Eqs. (70), (71), (74), and (77) into Eq. (68) results in the mass equation in the film boiling region:

$$
\begin{aligned}
& -\overline{\rho_{3}} A_{S} \frac{\mathrm{dL}_{2}}{\mathrm{dt}}-\bar{\rho}_{3} \mathrm{~A}_{\mathrm{S}} \frac{\mathrm{dL}}{\mathrm{dt}}+\mathrm{W}_{2}-\mathrm{W}_{3}-\mathrm{V}_{3}\left[\begin{array}{c}
\left(\rho_{\mathrm{g}}-\rho_{\mathrm{f}}\right)\left(\frac{\partial \overline{\alpha_{3}}}{\partial \mathrm{P}}+\frac{\partial \overline{\alpha_{3}}}{\partial \mathrm{X}} \frac{\partial \mathrm{X}}{\partial \mathrm{P}}\right) \\
+\overline{\alpha_{3}} \frac{\partial \rho_{\mathrm{g}}}{\partial \mathrm{P}}+\left(1-\overline{\alpha_{3}}\right) \frac{\partial \rho_{\mathrm{f}}}{\partial \mathrm{P}}
\end{array}\right] \frac{\mathrm{dP}}{\mathrm{dt}} \\
& =\mathrm{V}_{3}\left(\rho_{\mathrm{g}}-\rho_{\mathrm{f}}\right)\left(\frac{\partial \bar{\alpha}_{3}}{\partial \mathrm{G}}+\frac{\partial \overline{\alpha_{3}}}{\partial \mathrm{X}} \frac{\partial \mathrm{X}}{\partial \mathrm{G}}\right) \frac{\mathrm{dG}}{\mathrm{dt}}
\end{aligned}
$$

\subsubsection{Superheat Region}

For the superheat region the conservation of mass equation is

$$
\frac{d \bar{\rho}_{4} V_{4}}{d t}=W_{3}-W_{4}
$$


and the conservation of energy equation is

$$
\frac{d \overline{\rho_{4} h_{4}} V_{4}}{d t}-\frac{d\left(P_{4} V_{4}\right)}{d t}=W_{3} h_{3}-W_{4} h_{4}+Q_{4 s}-P_{4} \frac{d V_{4}}{d t}
$$

Expanding the derivative of the mass equation gives

$$
\overline{\rho_{4}} \frac{d V_{4}}{d t}+V_{4} \frac{d \overline{\rho_{4}}}{d t}=W_{3}-W_{4}
$$

Expanding the derivative in the energy equation yields

$$
V_{4} \frac{d \overline{\rho_{4} h_{4}}}{d t}+\overline{\rho_{4} h_{4}} \frac{d V_{4}}{d t}-V_{4} \frac{d P_{4}}{d t}=W_{3} h_{3}-W_{4} h_{4}+Q_{4 s}
$$

Multiplying the mass equation by the average enthalpy of the region and subtracting the result from the energy equation results in

$$
V_{4} \overline{\rho_{4}} \frac{d \overline{h_{4}}}{d t}-V_{4} \frac{d P_{4}}{d t}=W_{3}\left(h_{3}-\overline{h_{4}}\right)-W_{s t}\left(h_{s L}-\overline{h_{4}}\right)+Q_{4 S}
$$

where

$$
\begin{aligned}
& W_{4}=W_{S L}, \\
& h_{4}=h_{S L} .
\end{aligned}
$$

The average density of the superheat region is expressed as an average of the inlet and outlet densities:

where

$$
\bar{\rho}_{4}=\frac{\left(\rho_{3}+\rho_{4}\right)}{2}
$$

$$
\begin{aligned}
& \rho_{3}=\rho_{8}\left(P_{4}\right), \\
& \rho_{4}=\rho\left(P_{4}, h_{4}\right) .
\end{aligned}
$$


Similarly, the average enthalpy of the region is calculated as an average of the inlet and outlet enthalpies:

$$
\bar{h}_{4}=\frac{\left(h_{8}+h_{4}\right)}{2} \text {. }
$$

The volume of the superheat region is

$$
\mathrm{V}_{4}=\mathrm{A}_{5}\left(\mathrm{~L}-\mathrm{L}_{3}\right)
$$

and its time derivative is

$$
\frac{\mathrm{dV}_{4}}{\mathrm{dt}}=\mathrm{A}_{\mathrm{S}}\left(\frac{\mathrm{dL}}{\mathrm{dt}}-\frac{\mathrm{dL}_{3}}{\mathrm{dt}}\right)=-\mathrm{A}_{\mathrm{s}} \frac{\mathrm{dL}_{3}}{\mathrm{dt}}
$$

The average enthalpy of the superheat region is assumed to be a function of the enthalpy and pressure of the region:

$$
\overline{\rho_{4}}=f(h, P) \text {, }
$$

and its total time derivative is

$$
\frac{d \overline{\rho_{4}}}{d t}=\frac{\partial\left(\frac{\rho_{3}+\rho_{4}}{2}\right)}{\partial h} \frac{d h_{4}}{d t}+\frac{\partial\left(\frac{\rho_{3}+\rho_{4}}{2}\right)}{\partial P} \frac{d P_{4}}{d t}
$$

Substituting Eqs. (96) and (98) into Eq. (86) gives

$$
\mathrm{W}_{3}+\overline{\rho_{4}} \mathrm{~A}_{\mathrm{s}} \frac{\mathrm{dL} \mathrm{d}_{3}}{\mathrm{dt}}-\mathrm{V}_{4} \frac{\partial \overline{\rho_{4}}}{\partial \mathrm{h}} \frac{\mathrm{dh}}{\mathrm{dt}}+\mathrm{V}_{4} \frac{\partial \overline{\rho_{4}}}{\partial \mathrm{P}} \frac{\mathrm{dP}_{4}}{\mathrm{dt}}=\mathrm{W}_{\mathrm{SL}}
$$

Equations (17), (20), (64), (65), (82),(83),(88), and (99) form a set of eight nonlinear differential equations that contain fourteen variables that were reduced to eight by making the following assumptions:

$$
\begin{aligned}
& P_{1}=P_{2}=P_{3}=P_{4}=P_{S L} \\
& h_{1}=h_{f}\left(P_{S L}\right) \\
& h_{2}=h_{f}\left(1-X_{X D N B}\right)+X_{X D N B} h_{g} \\
& h_{3}=h_{B}\left(P_{S L}\right) .
\end{aligned}
$$


The eight nonlinear differential equations can be written in the following matrix form for numerical solution by Gaussian elimination: ${ }^{7}$

where

$$
A X=B
$$

$$
X=\left[\dot{\mathrm{h}}_{1}, \mathrm{~W}_{2}, \mathrm{~W}_{3}, \dot{\mathrm{L}}_{1}, \dot{\mathrm{L}}_{2}, \dot{\mathrm{L}}_{3}, \dot{\mathrm{P}}_{\mathrm{sL}}, \dot{\mathrm{h}}_{4}\right]^{\mathrm{T}}
$$

where $L_{1}, L_{2}$, and $L_{3}$ represent the location of the subcooled, nucleate boiling, and film boiling boundaries respectively. They represent the tube lengths from the feedwater entrance of the steam generator. $\mathrm{P}_{S L}$ and $\mathrm{h}_{\mathrm{SL}}$ represent the pressure and enthalpy of the leaving steam respectively. $\mathrm{W}_{2}$ and $\mathrm{W}_{3}$ represent the secondary flow rate across the nucleate/film boiling boundary and the film boiling/superheat boundary. The $h_{1}$ represents the enthalpy leaving the subcooled region. The elements of the $A$ and $B$ matrices are included in Appendix A.

A subroutine is used to solve the simultaneous equations by using the method of Gaussian elimination. To reduce the condition number of A, the flows are scaled by $10^{6}$. The second and third columns of the coefficient matrix $A$ are multiplied by $10^{6}$. The answers for the secondary mass flow rates $\mathrm{W}_{1}, \mathrm{~W}_{2}, \mathrm{~W}_{3}$ are also multiplied by $10^{6}$.

\subsection{PRIMARY SIDE EQUATIONS}

The primary side is divided into four regions by using the moving boundary defined by the secondary side equations. The primary volumes provide temperatures at the inlets and exits to define heat transfer rates conveniently. The heat transfer regions defined on the secondary side including the subcooled, nucleate boiling, film boiling, and superheat regions are the dividing lines for the axial moving boundaries. Both mass balance and energy balance equations are considered for describing the dynamics of each primary node. The primary sodium flow is assumed to remain single-phase liquid during all loadfollowing transients. The mass and energy equations are identical in all of the four primary side control volumes.

The mass balance equation is

$$
\frac{d \bar{\rho} V}{d t}=W_{\text {in }}-W_{\text {out }} \text {. }
$$

Taking the derivative and solving for the outgoing flow rate gives

$$
W_{\text {out }}=W_{\text {in }}-\bar{\rho} \frac{d V}{d t}-V \frac{d \bar{\rho}}{d t}
$$


Because the flow area of the primary sodium is constant and the sodium is treated as an incompressible fluid, the conservation of mass equation becomes

$$
W_{\text {out }}=W_{\text {in }}-\bar{\rho} \frac{d V}{d t}
$$

The conservation of energy equation is

$$
\frac{d \overline{\rho u} V}{d t}=W_{\text {in }} h_{\text {in }}-W_{\text {out }} h_{\text {out }}-Q_{P}-P \frac{d V}{d t}
$$

representing the above equation in terms of average enthalpy of the control volume results in

$$
\frac{d \overline{\rho h} V}{d t}=W_{\text {in }} h_{\text {in }}-W_{\text {out }} h_{\text {out }}-Q_{p}-V \frac{d P}{d t}
$$

Assuming the expansion work term $\mathrm{V} \mathrm{dP/dt}$ is negligible and expanding the derivative gives

$$
\overline{\rho h} \frac{d V}{d t}+V \frac{d \overline{\rho h}}{d t}=W_{\text {in }} h_{\text {in }}-W_{\text {out }} h_{\text {out }}-Q_{p}
$$

Multiplying the conservation of mass equation [Eq. (105)] by the average enthalpy of the control volume and subtracting from the above energy equation yields

$$
\bar{\rho} V \frac{d \bar{h}}{d t}=W_{\text {out }}\left(\bar{h}-h_{\text {out }}\right)+W_{\text {in }}\left(h_{\text {in }}-\bar{h}\right)-Q_{p} .
$$

Because of the negligible dependence of the enthalpy of the liquid sodium on pressure, the sodium enthalpy of a primary node is assumed to be a function of temperature only:

$$
h=h(T) \text {, }
$$

and its total derivative is

$$
\frac{d h}{d t}=\frac{\partial h}{\partial T} \frac{d T}{d t}=C_{p}(T) \frac{d T}{d t} .
$$


Substituting Eq. (111) into Eq. (109) and solving for the time derivative of the teniperature of the metal node yields

$$
\frac{d T_{p}}{d t}=\frac{\left[W_{o u t}\left(\bar{h}-h_{o u 1}\right)+W_{i n}\left(h_{i n}-\bar{h}\right)-Q_{p}\right]}{\rho V C_{p}}
$$

Because each region has moving boundaries, the inlet primary flow rate to each node is computed by using the expressions

$$
\begin{aligned}
& W_{p 1}=W_{\text {in }}-\overline{\rho_{1}} A_{p} \frac{d Z_{3}}{d t}, \\
& W_{P 2}=W_{i n}-\overline{\rho_{2}} A_{p} \frac{d Z_{2}}{d t}, \\
& W_{p 3}=W_{i n}-\overline{\rho_{3}} A_{p} \frac{d Z_{1}}{d t},
\end{aligned}
$$

where $\theta$ is the angle of incline of the helical tube with respect to the horizontal axis and is calculated by the expression

$$
\theta=\sin ^{-1}\left(\frac{Z}{L}\right)
$$

where $\mathrm{Z}$ is the height of the tube and $\mathrm{L}$ is the overall tube length. The heights of the subcooled, nucleate boiling, and film boiling regions are

$$
\begin{aligned}
& Z_{1}=L_{1} \sin \theta, \\
& Z_{2}=\left(L_{2}-L_{1}\right) \sin \theta, \\
& Z_{3}=\left(L_{3}-L_{2}\right) \sin \theta, \\
& Z_{4}=\left(L-L_{3}\right) \sin \theta ;
\end{aligned}
$$

and their time derivatives are

$$
\begin{aligned}
& \frac{\mathrm{dZ}_{1}}{\mathrm{dt}}=\sin (\theta) \frac{\mathrm{dL}_{1}}{\mathrm{dt}}, \\
& \frac{\mathrm{dZ}_{2}}{\mathrm{dt}}=\sin (\theta) \frac{\mathrm{dL}_{2}}{\mathrm{dt}}, \\
& \frac{\mathrm{dZ}_{3}}{\mathrm{dt}}=\sin (\theta) \frac{\mathrm{dL}_{3}}{\mathrm{dt}},
\end{aligned}
$$




$$
\frac{\mathrm{dZ}_{4}}{\mathrm{dt}}=-\sin (\theta) \frac{\mathrm{dL}_{3}}{\mathrm{dt}} .
$$

From Eq. (112), the equations of the temperature of the primary side nodes are

$$
\begin{aligned}
& \frac{d T_{p 1}}{d t}=\frac{\left[W_{\text {in }}\left(h_{\text {in }}-h_{p 1}\right)-W_{p_{1}}\left(h_{p_{1}}-h_{1 B}\right)-Q_{4 p}\right]}{\left[p_{1} V_{p 1} C_{p}\right]}, \\
& \frac{d T_{P 2}}{d t}=\frac{\left[W_{P 1}\left(h_{1 B}-h_{P 2}\right)+W_{P 2}\left(h_{P 2}-h_{2 B}\right)-Q_{3 p}\right]}{\left[P_{2} V_{P 2} C_{p}\right]}, \\
& \frac{d T}{d t}=\frac{\left[W_{P 2}\left(h_{2 B}-h_{p 3}\right)+W_{p 3}\left(h_{p 3}-h_{3 B}\right)-Q_{2 P}\right]}{\left[p_{3} V_{p 3} C_{p}\right]}, \\
& \frac{d T_{N A L}}{d t}=\frac{\left[W_{P 3}\left(h_{3 B}-h_{N A L}\right)-Q_{1 P}\right]}{\left[P_{4} V_{p 4} C_{p}\right]},
\end{aligned}
$$

where

$$
\begin{aligned}
& V_{P 1}=A_{p} Z_{1}, \\
& V_{P 2}=A_{p}\left(Z_{2}-Z_{1}\right), \\
& V_{P 3}=A_{p}\left(Z_{3}-Z_{2}\right), \\
& V_{p 4}=A_{p}\left(Z-Z_{3}\right) .
\end{aligned}
$$

The enthalpy of the primary fluid at the boundaries of the control volume depends on the sign of the flow rate through the boundary:

$$
\begin{aligned}
& h_{1 B}=\left\{\begin{array}{l}
h_{P_{1}}, w_{P_{1}} \geq 0 \\
h_{P 2}, W_{P 1} \leq 0
\end{array}\right. \\
& h_{2 B}=\left\{\begin{array}{l}
h_{P 2}, W_{P 2} \geq 0 \\
h_{P 3}, W_{P 2} \leq 0
\end{array}\right.
\end{aligned}
$$




$$
h_{3 B}=\left\{\begin{array}{l}
h_{P 3}, w_{P 3} \geq 0 \\
h_{\mathrm{NAL}}, W_{P 3} \leq 0
\end{array} .\right.
$$

\subsection{METAL TEMPERATURE EQUATIONS}

The metal side is divided into four nodes. With the moving boundary approach, the mass transfer due to the moving boundaries between regions has to be taken into account when deriving the energy equation associated with each metal node shown in Fig. 6.

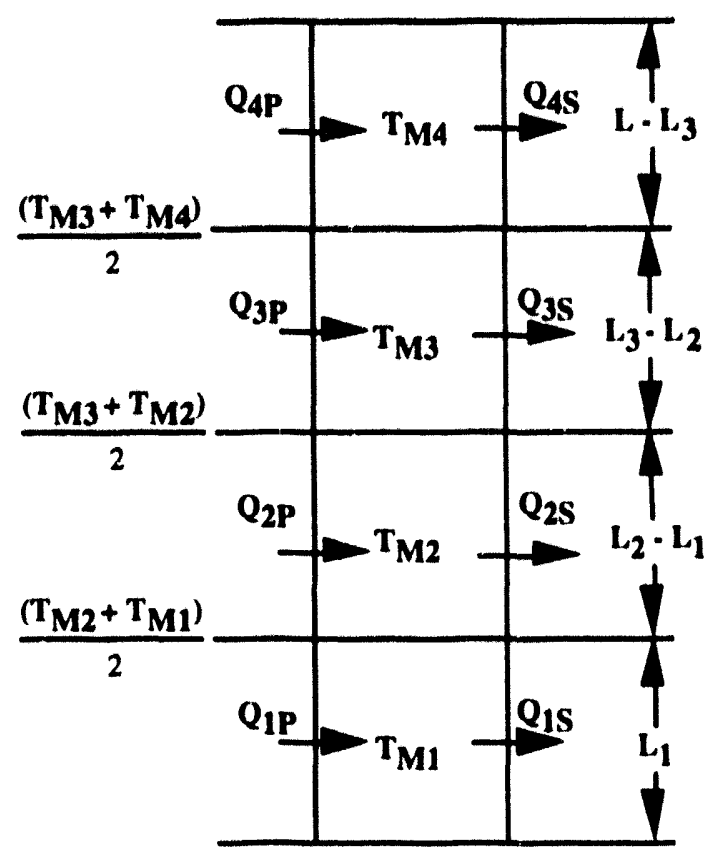

Fig. 6. Metal temperature nodes.

It is assumed that if the boundary is moving with a speed of $\mathrm{dL} / \mathrm{dt}$, it will add or subtract an amount of heat at a rate of $\rho_{m} A_{m} C_{m} T_{m} d L / d t$. 
The dynamic equations for the energy storage in the metal tube are formulated from the energy balance in the tube. The energy equations for the four metal nodes are given in Eqs. (136), (139), (140), and (141):

$$
\frac{d}{d t}\left(P_{m} A_{m} C_{m} L_{1} T_{m 1}\right)=Q_{1 P}-Q_{1 s}+P_{m} A_{m} C_{m} \bar{T} \overline{m 1} \frac{d L_{1}}{d t}
$$

The density and heat capacity of the metal node are assumed constant. Taking the derivative in Eq. (136) yields

$$
\begin{aligned}
& \rho_{m} A_{m} C_{m} L_{1} \frac{d T_{m 1}}{d t}+\rho_{m} A_{m} C_{m} T_{m 1} \frac{d L_{1}}{d t}= \\
& \quad Q_{1 P}-Q_{1 s}+\rho_{m} A_{m} C_{m}\left(\frac{T_{m 1}+T_{m 2}}{2}\right) \frac{d L}{d t} .
\end{aligned}
$$

Dividing through by $\rho_{m} A_{m} C_{m} L_{1}$ and collecting terms, then

$$
\frac{d T_{m 1}}{d t}=\frac{Q_{1 p}-Q_{1 S}}{\rho_{m} A_{m} C_{m} L_{1}}+\left(\frac{T_{m 2}-T_{m 1}}{2}\right) \frac{d L_{1}}{d t} .
$$

Similarly, the energy equations for the other three metal nodes are

$$
\begin{aligned}
& \frac{d}{d t}\left(\rho_{m} A_{m} C_{m}\left(L_{2}-L_{1}\right) T_{m 2}\right)=Q_{2 p}-Q_{2 s}+\rho_{m} A_{m} C_{m}\left(\frac{T_{m 3}+T_{m 2}}{2}\right) \frac{d L_{2}}{d t} \\
&-\rho_{m} A_{m} C_{m}\left(\frac{T_{m 1}+T_{m 2}}{2}\right) \frac{d L_{1}}{d t}, \\
& \frac{d}{d t}\left(\rho_{m} A_{m} C_{m}\left(L_{3}-L_{2}\right) T_{m 3}\right)=Q_{3 p}-Q_{3 s}+\rho_{m} A_{m} C_{m}\left(\frac{T_{m 3}+T_{m 4}}{2}\right) \frac{d L_{3}}{d t} \\
&-\rho_{m} A_{m} C_{m}\left(\frac{T_{m 3}+T_{m 2}}{2}\right) \frac{d L_{2}}{d t}, \\
& \frac{d}{d t}\left(\rho_{m} A_{m} C_{m}\left(L-L_{3}\right) T_{m 4}\right)=Q_{4 P}-Q_{4 s}-\rho_{m} A_{m} C_{m}\left(\frac{T_{m 3}+T_{m 4}}{2}\right) \frac{d l}{d t} .
\end{aligned}
$$


From the energy equations, the temperature equations for the three metal nodes are

$$
\begin{aligned}
\frac{d T_{m 2}}{d t} & =\frac{Q_{2 p}-Q_{2 s}}{\rho_{m} A_{m} C_{m}\left(L_{2}-L_{1}\right)}+\left(\frac{T_{m 2}-T_{m 1}}{2}\right) \frac{\left(\frac{d L_{2}}{d t}\right)}{\left(L_{2}-L_{1}\right)} \\
& -\left(\frac{T_{m 1}-T_{m 2}}{2}\right) \frac{\left(\frac{d L_{1}}{d t}\right)}{\left(L_{2}-L_{1}\right)}, \\
\frac{d T_{m 3}}{d t} & =\frac{Q_{3 p}-Q_{3 s}}{\rho_{m} A_{m} C_{m}\left(L_{3}-L_{2}\right)}+\left(\frac{T_{m 4}-T_{m 3}}{2}\right) \frac{\left(\frac{d L_{3}}{d t}\right)}{\left(L_{3}-L_{2}\right)} \\
& -\left(\frac{T_{m 2}-T_{m 3}}{2}\right) \frac{\left(\frac{d L_{2}}{d t}\right)}{\left(L_{3}-L_{2}\right)}, \\
\frac{d T_{m 4}}{d t} & =\frac{Q_{4 P}-Q_{4 s}}{\rho_{m} A_{m} C_{m}\left(L-L_{3}\right)}-\left(\frac{T_{m 3}-T_{m 4}}{2}\right) \frac{\left(\frac{d L_{3}}{d t}\right)}{\left(L-L_{3}\right)} .
\end{aligned}
$$

\subsection{MOMENTUM EQUATION}

The momentum conservation equation for the secondary tube length is obtained from summing up the region momentum equations. The average density of the secondary side is

$$
\bar{\rho}=\frac{\left[\overline{\rho_{1}} L_{1}+\overline{\rho_{2}}\left(L_{2}-L_{1}\right)+\overline{\rho_{3}}\left(L_{3}-L_{2}\right)+\overline{\rho_{4}}\left(L-L_{3}\right)\right]}{L} .
$$

The total momentum equation across the tube after summation includes terms for applied pressure differential, elevation storage, acceleration due to density changes, and friction:

$$
\frac{d}{d t} W_{S E}=\frac{g_{c} A_{S}}{L}\left(\begin{array}{l}
P_{S E}-P_{S L}-\overline{\rho_{1}} L_{1}-\overline{\rho_{2}}\left(L_{2}-L_{1}\right) \\
-\overline{\rho_{3}}\left(L_{3}-L_{2}\right)-\overline{\rho_{4}}\left(L-L_{3}\right)-\text { FRIC_LOSS + } \Delta P_{A C C}
\end{array}\right) \text {, }
$$

where $\triangle \mathrm{P}_{\mathrm{ACC}}$ represents the accelerational pressure drop and FRIC_LOSS represents the sum of frictional pressure drops in all regions. The frictional pressure drop in the 
subcooled, nucleate boiling, film boiling, and superheat region assuming turbulent flow are calculated as

subcooled region

$$
\Delta \mathrm{P}_{\mathrm{sc}}=\frac{\mathrm{KL} \mathrm{W}_{1} \mathrm{~W}^{2}}{\rho_{1}}
$$

nucleate boiling region

$$
\Delta P_{N B}=\frac{K\left(L_{2}-L_{1}\right) W^{2}}{P_{1}} \Phi_{2},
$$

film boiling region

$$
\Delta P_{F B}=\frac{K\left(L_{3}-L_{2}\right) W^{2}}{\rho_{1}} \Phi_{1} .
$$

superheat region

$$
\Delta P_{s H}=\frac{K\left(L-L_{3}\right) W^{2}}{P_{4}}
$$

Hence,

FRIC_LOSS $=K W_{\text {SE }}^{2}\left(\frac{L_{1}}{\rho_{1}}+\frac{\left(L_{2}-L_{1}\right)}{\rho_{1}} \phi_{2}+\frac{\left(L_{3}-L_{2}\right)}{\rho_{1}} \phi_{3}+\frac{\left(L-L_{3}\right)}{\rho_{4}}\right)$.

To obtain the frictional pressure loss for two-phase flow, the single-phase friction coefficient is corrected by the Martinelli Nelson empirical approximation of the iwophase multiplier. The two-phase multiplier is as a function of steam quality, pressure, and mass flow rate as

$$
\Phi=\operatorname{GTP}\left[1.2\left(\frac{\rho_{\mathrm{f}}}{\rho_{\mathrm{t}}}-1.0\right) \mathrm{X}_{\mathrm{DNZ}}^{0824}\right]+1.0
$$

where

$$
G T P=\left\{\begin{array}{l}
1.36+0.0005 P_{\text {st. }}+0.1\left(\frac{G}{10^{6}}\right)-0.000714 P_{\text {si }}\left(\frac{G}{10^{6}}\right) \cdot\left(\frac{G}{10^{6}}\right)<0.7 \\
1.26-0.0004 P_{\text {st. }}+0.119\left(\frac{10^{6}}{G}\right)+0.00028 P_{\text {si. }}\left(\frac{10^{6}}{G}\right),\left(\frac{G}{10^{6}}\right)>0.7
\end{array}\right\} .
$$




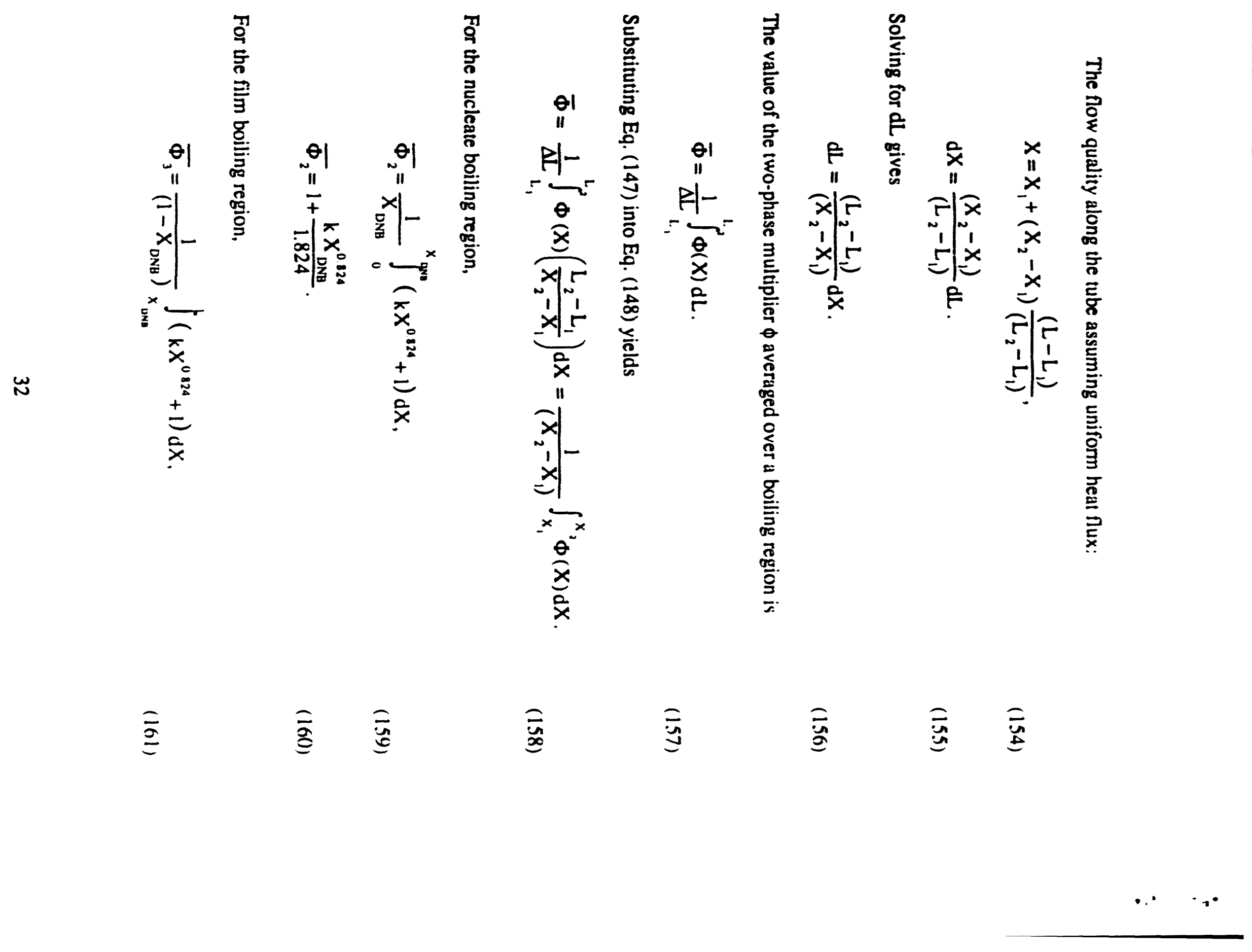




$$
\Phi_{3}=1+\frac{k\left(1-X_{D N B}^{1824}\right)}{1.824\left(1-X_{D N B}\right)}
$$

The accelerational pressure drop is due to the velocity change as the fluid accelerates from liquid phase to vapor phase. The term is calculated by using the equation

$$
\Delta P_{A C C}=K W_{S E}^{2}\left(\frac{W_{s E}}{A_{S}}\right)^{2}\left(\frac{1}{\rho_{S E}}-\frac{1}{\rho_{S L}}\right) .
$$

\subsection{SUMMARY OF HEAT TRANSFER CORRELATIONS}

In this section, the heat transfer characteristics of the steam generator and the corresponding correlations are presented. These correlations are used in both steady-state and dynamic thermal-hydraulic transients. Also, the physical and thermodynamic properties of the primary liquid sodium, water/steam mixture, and tube metal used in the steam generator model are presented.

The relationships used for the primary and secondary heat transfer effectivenesses were obtained from notes from personal communication with $T$. $L$. Wilson of Oak Ridge National Laboratory and are reproduced here. The heat transfer from the sodium to the tube metal and from the tube metal to water is assumed to be due entirely to convection. The heat transfer from the hot sodium to the metal tube is calculated by using

$$
Q_{i p}=U_{E F P}\left(T_{M}-T_{\text {cin }}\right),
$$

and the heat transfer between the tube metal and the secondary node is given b;

$$
Q_{i S}=U_{E F S}\left(T_{H A n}-T_{M}\right),
$$

where $T_{M}$ is the metal temperature, $T_{\text {cio }}$ is the temperature of cold fluid in, $t_{\text {hin }}$ is the temperature of hot fluid in, and $\mathrm{U}_{\mathrm{EFP}}$ and $\mathrm{U}_{\mathrm{EFS}}$ are primary and secondary effectiveness coefficients of the counterflow geometry of the tube metal. Then,

$$
U_{\mathrm{EFA}}=\frac{2 g-g^{2}\left(1-C_{k}\right)}{f+g-f g\left(1-C_{R}\right)(2 g+3)}
$$




$$
\begin{aligned}
U_{B F S t}= & \frac{2 g-g^{2}\left(1-C_{R}\right)}{1-f+g-g(1-f)\left(1-C_{R}\right)}, \\
g & =R C_{R}-\frac{f}{1-f}, \\
f & =\frac{U_{H}}{U_{H}+U_{C}},
\end{aligned}
$$

with

$$
\begin{aligned}
& R=e^{\frac{-U p .}{C_{11}}\left(1-C_{n}\right)}, \\
& U_{11}=\frac{1}{\frac{1}{h_{11}}+\frac{a}{2 k}}, \\
& U_{C}=\frac{1}{\frac{1}{h_{c}}+\frac{a}{2 k}}, \\
& C_{R}=\frac{C_{11}}{C_{c}}, \\
& C_{H}=\left(W C_{p}\right)_{n 1} \\
& C_{C}=\left(W C_{p}\right)_{c},
\end{aligned}
$$

where

$$
\begin{aligned}
& h=\text { heat transfer coefficient, } \\
& U \text { = overall heat transfer coefficient, } \\
& L=\text { length of tube, } \\
& P \text { wetted perimcter, } \\
& W=\text { fluid flow rate, } \\
& C_{P}=\text { specific heat of fluid, } \\
& a=\text { thickness of tube, } \\
& k \text { = tube conductivity, }
\end{aligned}
$$

and the subscripts $\mathrm{H}$ and $\mathrm{C}$ denote hot and cold fluid respectively. 
The heat transfer coefficients used in the secondary side of the steam generator are computed by using the empirical correlations given below.

\subsubsection{Subcooled Region}

The convective heat transfer coefficient for the fully developed turbulent flow in the subcooled region is calculated from the Dittus-Boelter ${ }^{9}$ correlation:

$$
\mathrm{Nu}=0.023 \mathrm{R}_{\mathrm{e}}^{0.8} \mathrm{P}_{\tau}^{0.4}
$$

where $\mathrm{Nu}, \mathrm{R}_{\mathrm{e}}$, and $\mathrm{P}_{\mathrm{r}}$ are Nusselt, Reynolds, and Prandtl numbers respectively. They are represented by the expressions

$$
\mathrm{Nu}=\frac{h \mathrm{D}}{\mathrm{k}}, \mathrm{R}_{\mathrm{c}}=\frac{\mathrm{Dup}}{\mu} \text {, and } \mathrm{P}_{\mathrm{r}}=\frac{\mathrm{C} \mu}{\mathrm{k}} \text {, }
$$

where

$$
\begin{aligned}
& h=\text { heat transfer coefficient, } \\
& \rho=\text { density of the fluid, } \\
& \mu=\text { viscosity of the fluid, } \\
& C=\text { specific heat of the fluid, } \\
& D=\text { diameter of the tube } \\
& k=\text { thermal conductivity of the fluid, } \\
& u=\text { velocity of the fluid. }
\end{aligned}
$$

The total heat transfer coefficient is dependent on density, velocity, viscosity, and conductivity of the fluid. However, the density and velocity of the fluid are more apt to change value during a given transient than are other properties, indicating that they are miure predominant. Therefore, the simplified form is used for the heat transfer coefficient:

$$
h=k_{c} W^{0.8}
$$

where $\mathrm{k}_{\mathrm{c}}$ is a multiplying factor and $\mathrm{W}$ is the secondary mass flow rate.

The Dittus-Boelter correlation is valid for fully developed turbulent flow in smooth tubes. It is applicable for fluid with small temperature differences and $0.7<\operatorname{Pr}<1(0)(0)$, $\operatorname{Re}>10000$, and $L / D>60$ (reference 9 ). The fluid properties are evaluated at the fluid bulk temperature at the region of interest. 


\subsubsection{Nucleate Boiling Region}

The heat transfer coefficient for the two-phase nucleate boiling region is calculated by using Thom's correlation. ${ }^{10}$ This correlation is sensitive to the pressure of the system and is presented by

$$
\mathrm{h}^{\mathrm{Thom}}=\left[\frac{\mathrm{e}^{\left(\frac{\mathrm{p}}{1260}\right)}}{0.072}\right] \mathrm{Q}^{0.5},
$$

and the heat transfer $\mathrm{Q}$ is calculated as

$$
\begin{aligned}
& Q=h^{T h o m} \Delta T \\
& Q=\left(\frac{e^{\left(\frac{p}{1260}\right)}}{0.072}\right) Q^{0.5} \Delta T \\
& Q=\left[\left(\frac{e^{\left(\frac{p}{1260}\right)}}{0.072}\right) \Delta T\right]^{2}
\end{aligned}
$$

with

where

$$
\Delta \mathrm{T}=\left(\mathrm{T}_{\text {wall }}-\mathrm{T}_{\mathrm{SAT}}\right)
$$

$$
\begin{aligned}
& \mathrm{P} \quad=\text { pressure in psia, } \\
& \mathrm{T}_{\text {wall }}=\text { wall temperature, } \\
& \mathrm{T}_{\mathrm{SAT}}=\text { saturation temperature of the secondary fluid. }
\end{aligned}
$$

\subsubsection{Film Boiling Region}

The heat transfer coefficient for the two-phase mixture within the film boiling region is obtained from the Modified Bishop correlation ${ }^{11}$

$$
h=\mathrm{KW}^{0.8}\left[\mathrm{X}_{\mathrm{XDNB}}+\left(1-\mathrm{X}_{\mathrm{XDNB}}\right) \frac{\rho_{\mathrm{g}}}{\rho_{\mathrm{f}}}\right]^{0.68}\left(\frac{\rho_{\mathrm{g}}}{\rho_{\mathrm{f}}}\right)^{0.068},
$$

where the effects of the Prandtl number are neglected.

The Modified Bishop correlation is valid for systems with high pressures and assumes complete thermal equilibrium between the two phases. 


\subsubsection{Superheat Region}

Similar to the subcooled region, the superheat single-phase convection uses the same correlation as the subcooled region Dittus-Boelter correlation:

$$
\mathrm{h}=\mathrm{KW}^{0.8} \text {. }
$$

\subsubsection{Primary Side}

The heat transfer correlation for the primary sodium flow is obtained from MaroscaDwyer correlation. ${ }^{12}$ The Nusselt number is expressed as

$$
\mathrm{Nu}=6.66+3.126 * \frac{\mathrm{p}}{\mathrm{do}}+1.184 *\left(\frac{\mathrm{p}}{\mathrm{do}}\right)^{2}+0.0155\left(\bar{\psi} \mathrm{P}_{\mathrm{e}}\right)^{0.86}
$$

with

$$
\bar{\psi}=1-\frac{1.82}{\mathrm{P}_{\mathrm{r}}\left\langle\left(0.4824+0.88 \frac{\mathrm{do}}{\mathrm{p}}\right)\left\{2+2.15 \times 10^{-3}\left[\left(0.4824+0.88 \frac{\mathrm{do}}{\mathrm{p}}\right) \mathrm{R}_{\mathrm{e}}\right]^{0.88}\right\}\right\rangle^{14}}
$$

where $\mathrm{p} / \mathrm{do}$ is the pitch-to-diameter ratio. Neglecting the Prandtl number effect and for the primary flow range of interest, the heat transfer coefficient for the primary side coolant is

$$
\mathrm{h}=\mathrm{KW}_{\mathrm{NAE}} \text {, }
$$

where $\mathrm{W}_{\mathrm{NAE}}$ is the primary sodium flow rate.

\subsection{THERMODYNAMIC AND PHYSICAL PROPERTIES OF SODIUM, WATER AND TUBE METAL}

The properties of liquid sodium, steam/water, and the metal tube used in the development of the dynamic model of the steam generator are listed in this section.

\subsubsection{Sodium Properties}

The thermodynamic relationships between temperature, specific heat, and enthalpy for the primary sodium were obtained from internal correspondence from J. C. Cleveland et al., Oak Ridge National Laboratory. 
3.9.1.1 Sodium density. The liquid sodium is treated as an incompressible fluid. Its density is represented as a function of temperature only:

$$
\rho=59.566-7.9504 \times 10^{-3} \mathrm{~T}_{\mathrm{F}}-0.2872 \times 10^{-6} \mathrm{~T}_{\mathrm{F}}^{2}+0.06035 \times 10^{-9} \mathrm{~T}_{\mathrm{F}}^{3},
$$

where $\rho$ is in pounds mass per cubic foot and $T_{F}$ is in degrees Fahrenheit. This equation is valid for $208<\mathrm{T}_{\mathrm{F}}<2500^{\circ} \mathrm{F}$.

3.9.1.2 Specific heat of sodium. The specific heat of sodium is considered to be a function of temperature only. The specific heat at constant pressure of liquid sodium is obtained from the expression

$$
\mathrm{C}_{\mathrm{P}}=0.389352-1.10599 \times 10^{-4} \mathrm{~T}_{\mathrm{R}}+3.41178 \times 10^{-8} \mathrm{~T}_{\mathrm{R}}^{2},
$$

where $C_{p}$ is the specific heat in British thermal units per pound mass per degree Fahrenheit and $T_{R}$ is the temperature in degrees Rankine.

3.9.1.3 Enthalpy of sodium. The enthalpy is obtained from

$$
h(T)=\int_{T_{R \in c}}^{T} C_{p}\left(T^{\prime}\right) d T^{\prime},
$$

where $\mathrm{C}_{\mathrm{p}}\left(\mathrm{T}^{\prime}\right)$ is given in Eq. (190) and $\mathrm{T}_{\mathrm{Ref}}$ is taken as $100^{\circ} \mathrm{C}$.

\subsubsection{Steam/Water Properties}

The physical and thermodynamic properties of the steam/water mixture are evaluated by using the Modular Modeling System ${ }^{13}$ steam-water library, which contains a set of steam/water property routines. Some of these routines are polynomials, and others are table interpolations of the thermodynamic properties of steam and water. Given the pressure and the enthalpy, the subroutines determine the water phase and the appropriate density, temperature, and partials of density with respect to pressure and enthalpy. In the derivation of the state equations of the two-phase regions, the water properties are determined as a function of the void fraction of the corresponding region. The saturated vapor and liquid properties needed in these state equations are determined from the appropriate functions of pressure. 


\subsubsection{Physical Properties of the Metal Tube}

Both the density and the specific heat of the metal tube are assumed constant.

3.9.3.1 Density of the metal tube.

$$
\rho_{\mathrm{m}}=486.7 \mathrm{lb}_{\mathrm{m}} / \mathrm{ft}^{3} \text {. }
$$

3.9.3.2 Specific heat of the metal tube.

$$
\mathrm{C}_{\mathrm{m}}=0.135 \mathrm{Btu} / \mathrm{lb}_{\mathrm{m}}{ }^{-0} \mathrm{~F} \text {. }
$$




\section{RESULTS AND DISCUSSION}

This section presents the transient response of selected variablies to ramp changes in the boundary conditions for flow, temperature, and pressure. To simulate steady-state conditions of the steam generator at $100 \%$ rated power, the departure from nucleate boiling correlation [Eq. (8)] and the heat transfer effectiveness for each of the primary and secondary regions were modified by correction factors such that the primary and secondary heat balance became equal to $479 \mathrm{MW}(\mathrm{t})$. These correction factors were introduced to account for the helical geometry of the tubes and its effects on the heat transfer coefficients. The simulated steady-state conditions at $10(0 \%$ rated power are listed in Table 1. These conditions were obtained by using a proportional-integral controller to control the pressure of the steam to its set point such that the steam flow rate is

$$
W_{s t}=W_{s 11}\left(\frac{Q_{s p}}{Q_{\text {max }}}\right)\left[\int_{0}^{1} K_{1}\left(P_{s t}-P_{s p}\right) d t+K_{I P}\left(P_{s t}-P_{s p}\right)\right]
$$

where $\mathrm{K}_{\mathrm{I}}$ and $\mathrm{K}_{\mathrm{IP}}$ are the integral and proportional gains and

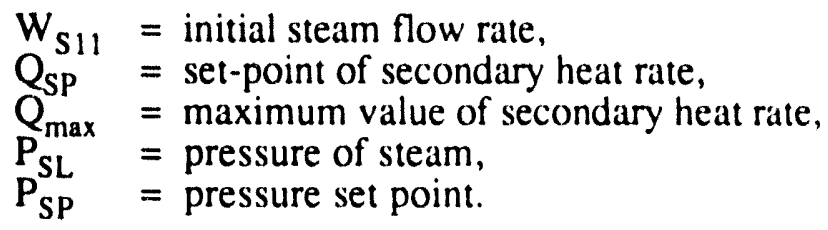

To demonstrate the model's ability to simulate steam generator behavior for a wide range of perturbations, transients induced by introducing perturbations in each of the boundary conditions are investigated. The possible perturbations are changes in primary coolant inlet temperature, primary coolant flow rate, feedwater flow rate, and outlet steam pressure. An $80 \%$ decrease in feedwater flow transient is also investigated.

These transients are of special interest because they provide information on the steam generator nonlinear behavior. For each case, the input variable under study is perturbed from its steady-state operating point by a $10 \%$ ramp increase, with the other four input variables held constant. In all cases, a period of steady-state operation for $500 \mathrm{~s}$ is simulated before the beginning of the transient "n ensure that the simulation is stabilized and that subsequent variations are due to the perturbation induced rather than to an offset in the initial conditions.

One of the limitations of the steam generator model is that the subcooled, nucleate boiling, film boiling, and superheat regions must be present during all investigated transients. To prevent the disappearance of the film boiling region in the $80 \%$ reduction in feedwater flow transient, the steam quality was not allowed to decrease beyond 0.99 . 
Table 1: Simulated steady-state conditions at $100 \%$ rated power

Heat load, MW(t)

Inlet feedwater temperature, ${ }^{\circ} \mathrm{F}$

Outlet steam temperature, ${ }^{\circ} \mathrm{F}$

Outlet steam pressure, psia

Inlet sodium temperature, ${ }^{\circ} \mathrm{F}$

Outlet sodium temperature, ${ }^{\circ} \mathrm{F}$

Feedwater flow rate, $1 b_{m} / h$

Sodium flow rate, $\mathrm{lb}_{\mathrm{m}} / \mathrm{h}$

Length of subcooled region, $\mathrm{ft}$

Length of nucleate boiling region, $\mathrm{ft}$

Length of film boiling region, $\mathrm{ft}$

Length of superheat region, $\mathrm{ft}$

Temperature of primary node $1,{ }^{\circ} \mathrm{F}$

Temperature of primary node $2,{ }^{\circ} \mathrm{F}$

Temperature of primary node $3,{ }^{\circ} \mathrm{F}$

Temperature of metal node $1,{ }^{\circ} \mathrm{F}$

Temperature of metal node $1,{ }^{\circ} \mathrm{F}$

Temperature of metal node $1,{ }^{\circ} \mathrm{F}$

Temperature of metal node $1,{ }^{\circ} \mathrm{F}$

Steam quality
477.2

380

830

$18(0)$

864

577

$1.6056 \times 10^{6}$

$1.8230 \times 10^{7}$

95.823

58.156

7.782

81.24

8() 1.87

773.08

659.29

558.71

635.36

642.52

779.98

0.7991

\subsection{0\% INCREASE IN PRIMARY COOLANT INLET TEMPERATURE}

Figure 7 depicts the inlet and outlet sodium temperatures and the steam outlet temperature during the $10 \%$ increase in inlet sodium temperature transient. The inlet sodium temperature was held constant at $864^{\circ} \mathrm{F}$ for $500 \mathrm{~s}$ and then allowed to increase by 86.4 to $950.4^{\circ} \mathrm{F}$ in $200 \mathrm{~s}$, where it is maintained constant for the rest of the transient. The increase in sodium inlet temperature causes an increase in the rate of heat transfer from the primary side of the steam generator to the secondary side through the wall of the metal tube. As a result, an increase in all temperatures of the system is observed. The sodium outlet temperature and the steam outlet temperature are fairly sensitive 10 the increase in the sodium inlet temperature. Each temperature steadily increases to a new steady state. The sodium and steam outlet temperature increased by 67.34 and $104^{\circ} \mathrm{F}$ respectively. Figure 8 shows changes in subcooled, nucleate boiling, film boiling, and superheat regions during the transient. As shown, the lengths of the subcooled, nucleate boiling, and film boiling regions decrease, whereas the length of the superheat region increases. Figure 9 depicts the inlet feedwater pressure during this transient. This pressure increases because of a larger pressure drop, with the largest pressure drop taking place across the superheat region. Figure 10 depicts the rate of steam flow out of the steam generator. The steam flow rate initially rises and then approaches its old steady-state value because there is no increase in feedwater flow to maintain the rise. 


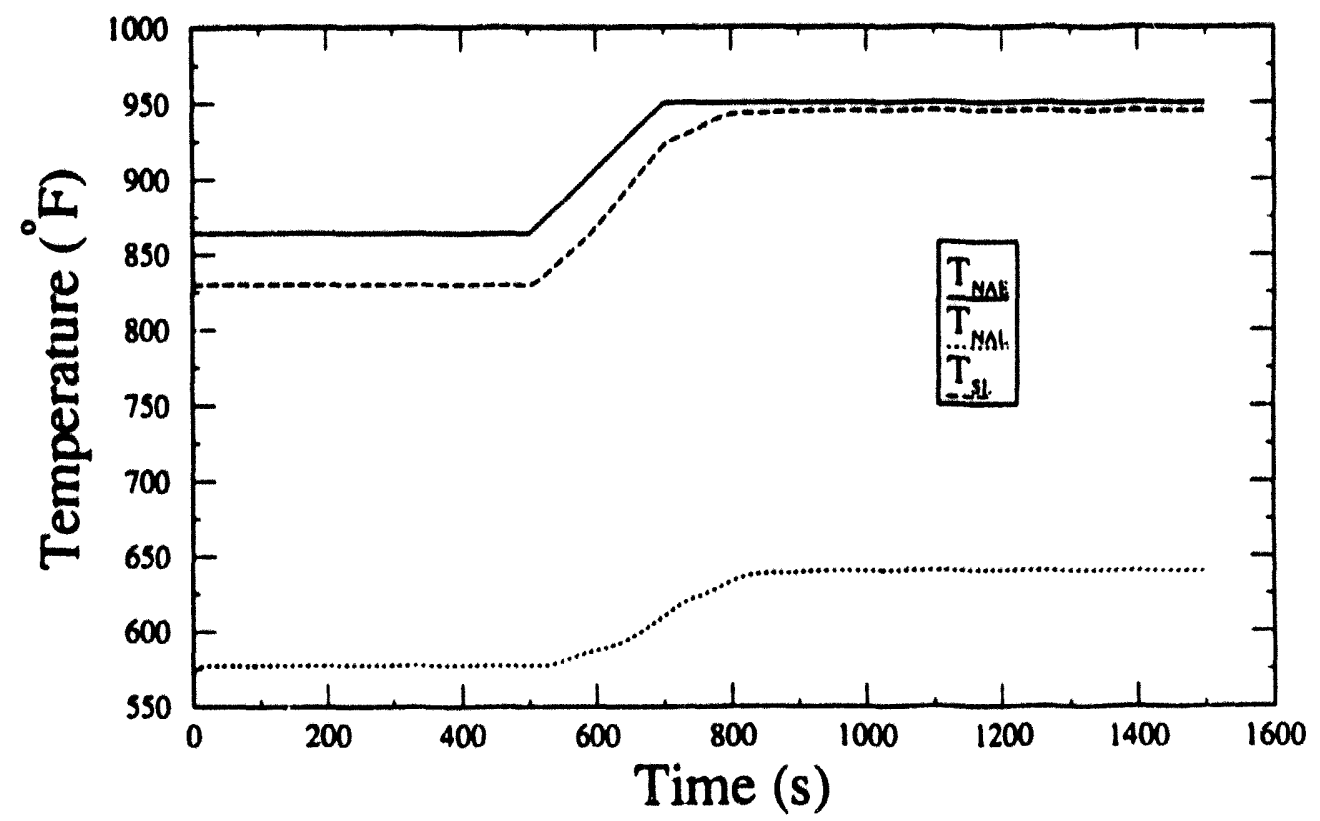

Fig. 7. Inlet and outlet sodium temperatures and the steam outlet temperature following a $10 \%$ increase in inlet sodium temperature transient.

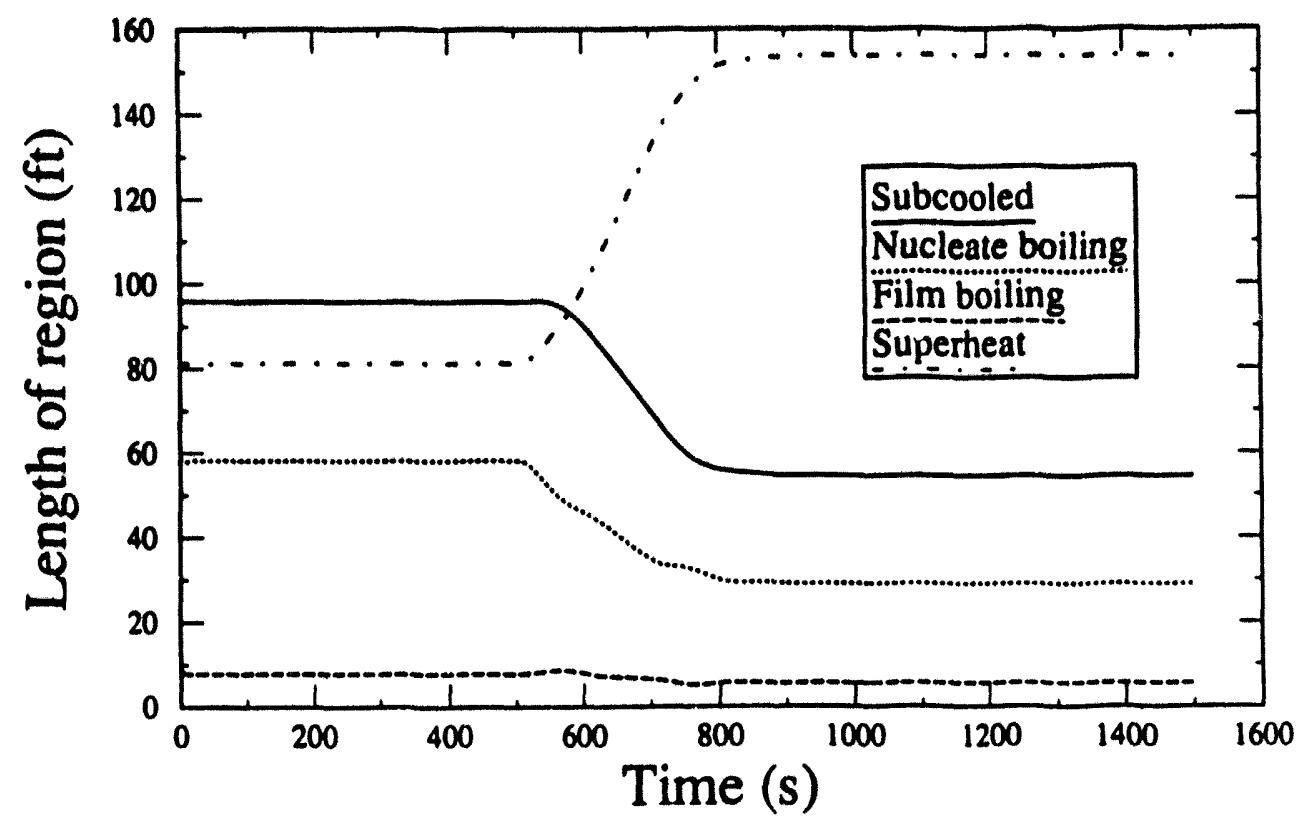

Fig. 8. Lengths of the subcooled, nucleate boiling, film boiling and superheat regions during the $10 \%$ increase in inlet sodium temperature transient. 


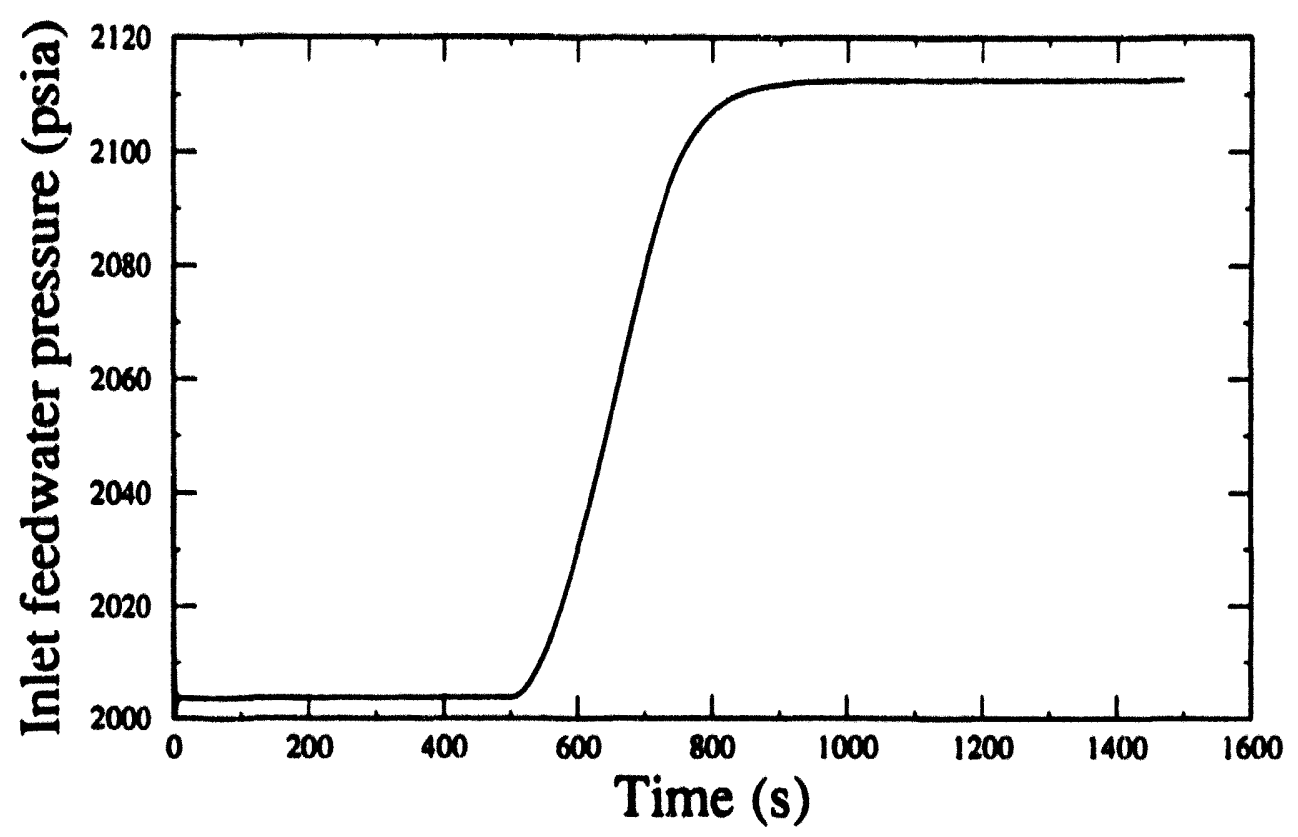

Fig. 9. Inlet feedwater pressure during the $10 \%$ increase in inlet sodium temperature transient.

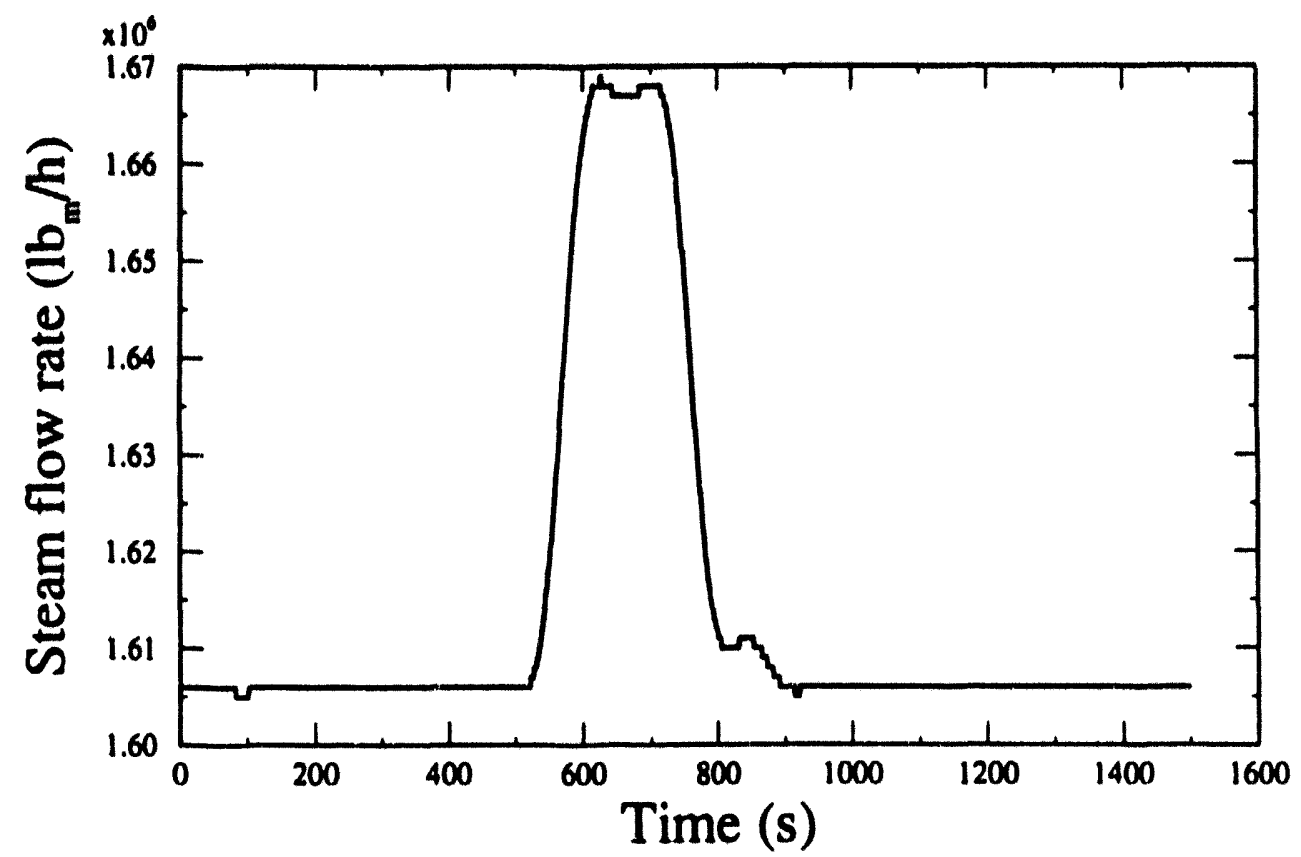

Fig. 10. Rate of steam flow out of the steam generator during the $10 \%$ increase in inlet sodium temperature transient. 


\subsection{0\% INCREASE IN PRIMARY COOI.ANT FLOW RATE}

Figure 11 shows the transient response for a $10 \%$ increase in primary coolant flow rate, with the other four input variables held constant. The sodium flow rate is majintained at $1.823 \times 10^{7} \mathrm{lh} / \mathrm{h}$ for $500 \mathrm{~s}$ and then is allowed 0 increase $102.0053 \times$ $10^{7} \mathrm{Ih} / \mathrm{m}$ within $2(X) \mathrm{s}$, after which is maintained at the new rate for the remainder of the transient. Figures 12,13, and 14 depict the length of each of the four secondary side regions, the inlet feedwater pressure, and the steam outlet flow rate respectively.

The 10\% increase in primary flow ratc causes an increase in the rate of transfer of thermal energy to the secondary coolant through the tube metal wall. The system transient responses [Figs. $11-14$ | are qualitatively similar to those produced in the $10 \%$ increase in primary sodium inlet temperature transient, but these process variables are less quantitatively perturbed.

\subsection{0\% INCREASE IN FEEDWATER FLOW RATE}

Figures 15-18 show the steam generator responses for a $10 \%$ increase in the feedwater flow rate transient, with the other input variables held constant. Figure 15 represents the steam flow rate out of the steam generator during the transient and, as seen, it responds to the increased feedwater flow and essentially equals the increased feedwater flow within a few seconds. For a constant primary flow rate and inlet sodium temperature, the temperatures of the secondary side of the steam generator decrease hecause of the increase in the feedwater flow. Consequently, the lengths of the subcooled, nucleate boiling. and film boiling regions increase, whereas the length of the superheat region decreases. Figures 16 and 17 depict the lengths of the four regions of the secondary side of the steam generator and the temperature of the outgoing steam and outgoing sodium respectively. Figure 18 depicts the feedwater inlet pressure during the transient. The increase in feedwater flow causes a larger pressure drop across the steam generator, and as a result, the inlet feedwater pressure experiences a slight increase initially. Subsequently, the decrease in the length of the superheated region overcompensates for the increase in the feedwater flow rate, and the inlet feedwater pressure approaches a value slightly lower than its initial value.

\subsection{0\% INCREASE IN OUTLET STEAM PRESSURE}

Figure 19 represents the feedwater inlet pressure and the steam outlet pressure during the $10 \%$ increase in outlet steam pressure transient. The outlet steam pressure is maintained at $180(0)$ psi for $5(0) \mathrm{s}$ and then is allowed to increase to 1980 psi within $200 \mathrm{~s}$. after which it is maintained at $1980 \mathrm{psi}$ for the remainder of the transient. During this transient, the primary coolant flow rate, primary coolant inlet temperalure, and inlet feedwater flow rate were held constant at $1.823 \times 10^{7} \mathrm{lb} / \mathrm{h}, 864^{\prime \prime} \mathrm{F}$, and $1.6056 \mathrm{X}$ $10^{6} \mathrm{Jh} / \mathrm{h}$ respectively.

Because the feedwater flow rate is unchanged, the fluid pressure throughout the steam generator increases. This increase results in a decrease in the length of the nucleate boiling and superheat regions and an increase in the lengths of the subcooled and film 


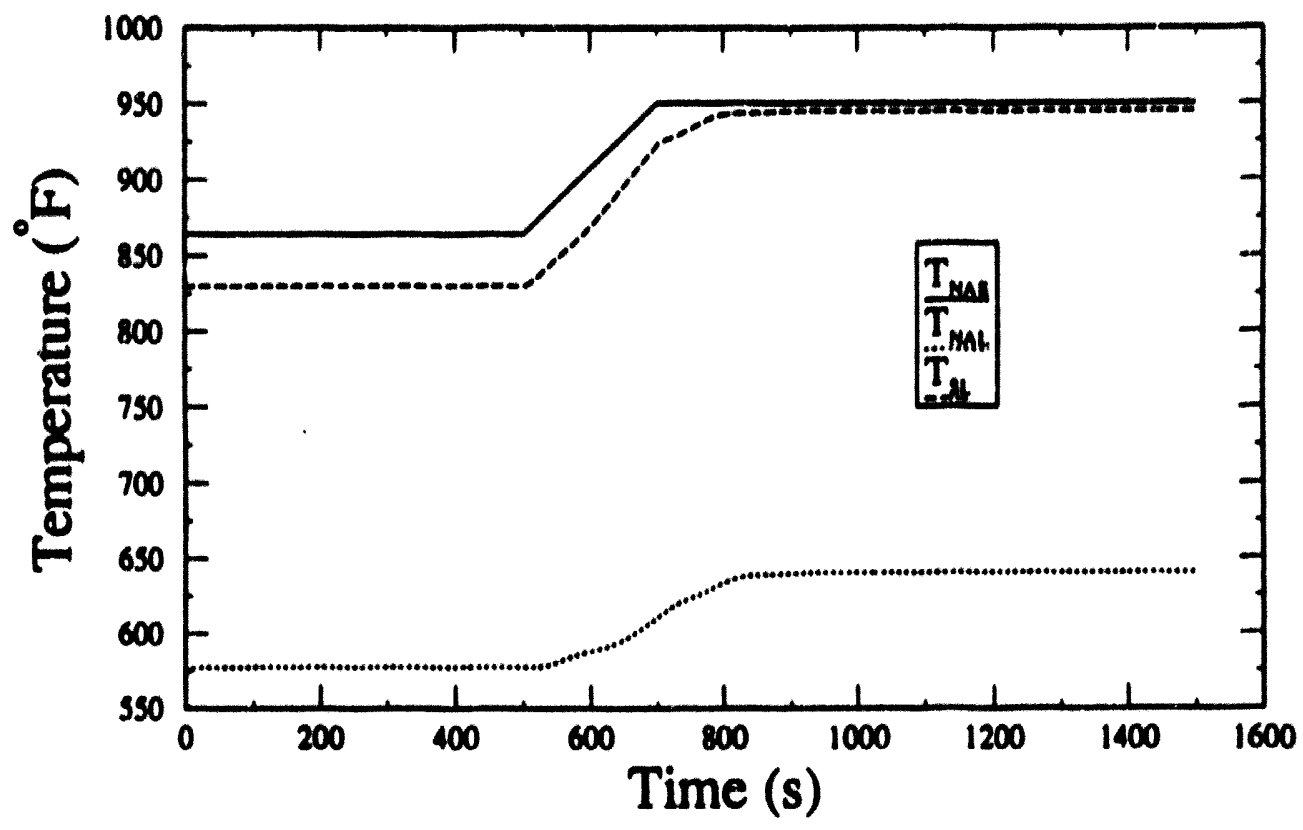

Fig. 11. Primary coolant flow rate during the $10 \%$ increase in primary coolant now rate transient.

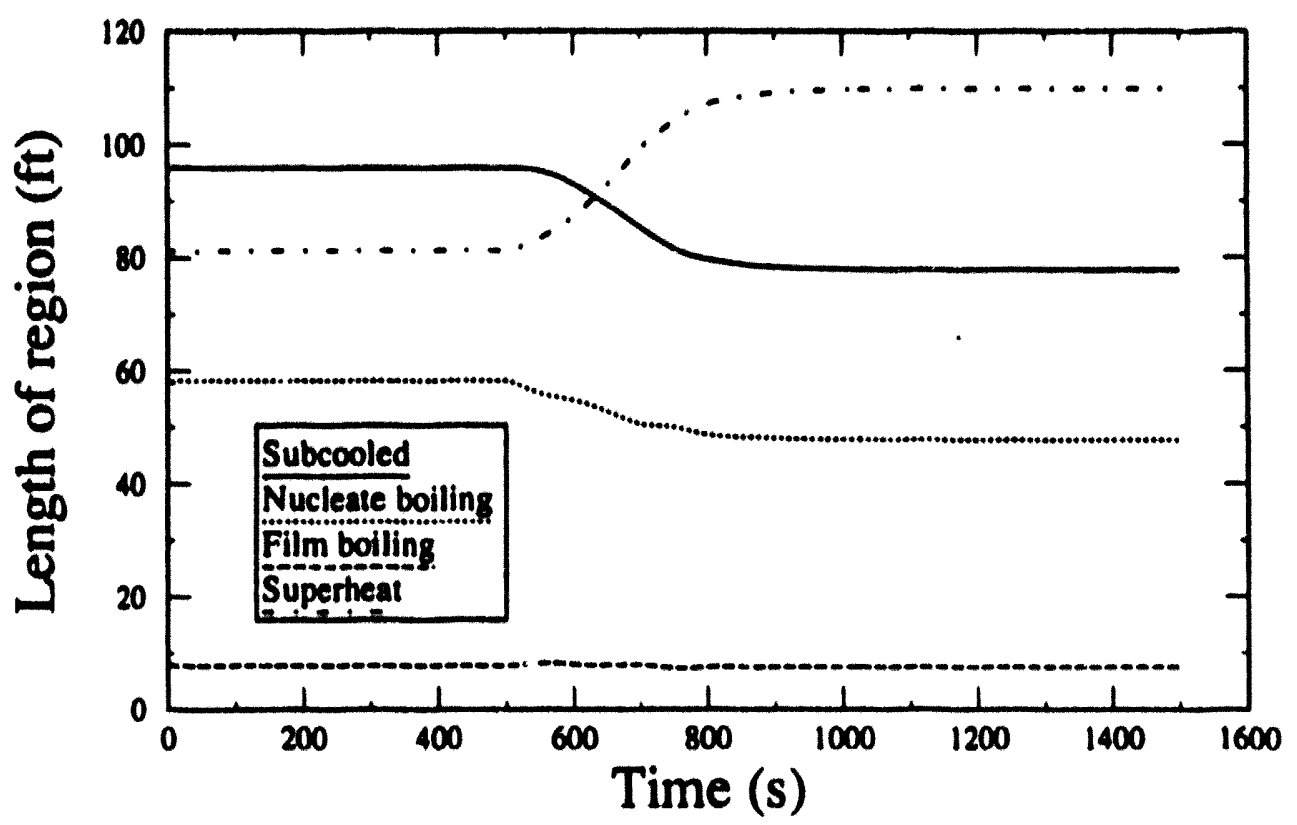

Fig. 12. Lengths of the subcooled, nucleate boiling, nim boiling and superheat regions during the $10 \%$ increase in primary coolant now rate transient. 


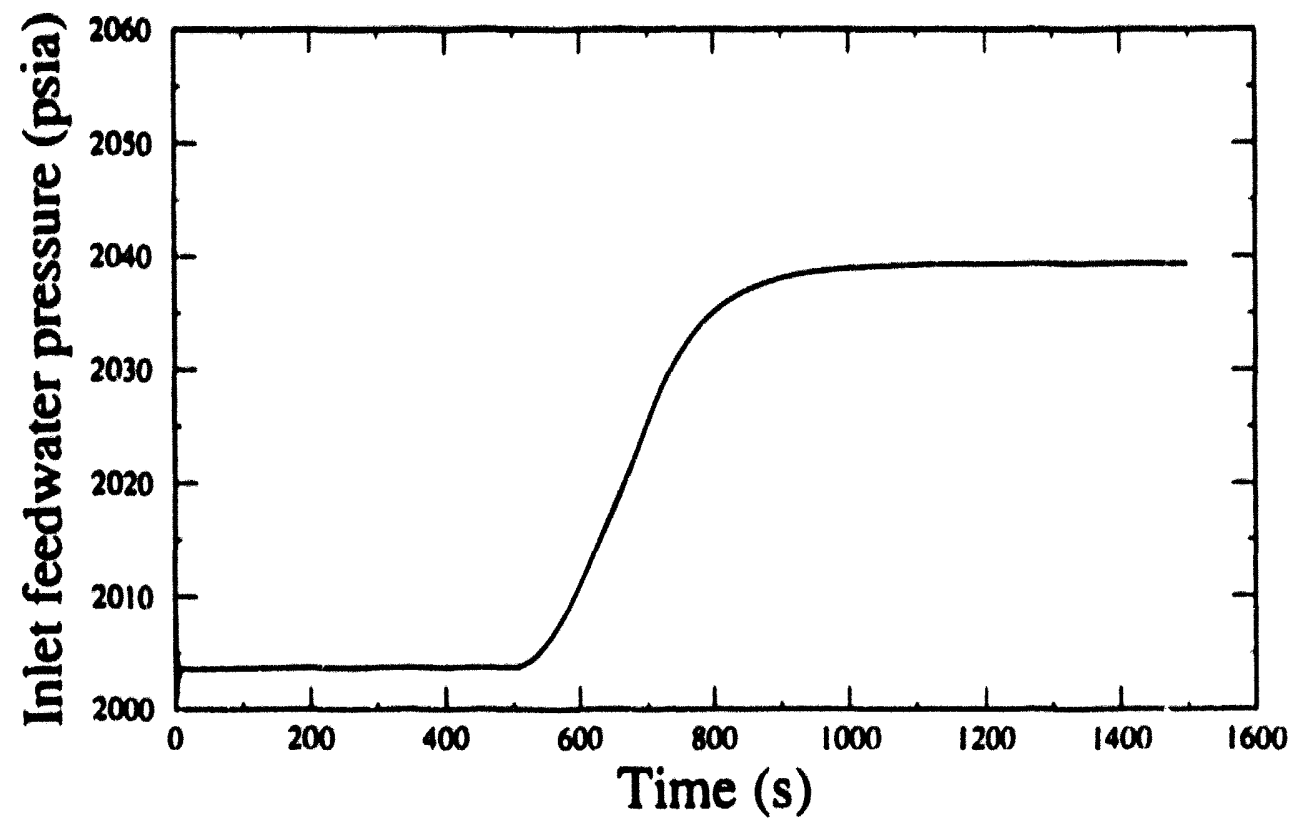

Fig. 13. Inlet feedwater pressure during the $10 \%$ increase in primary coolant flow rate transient.

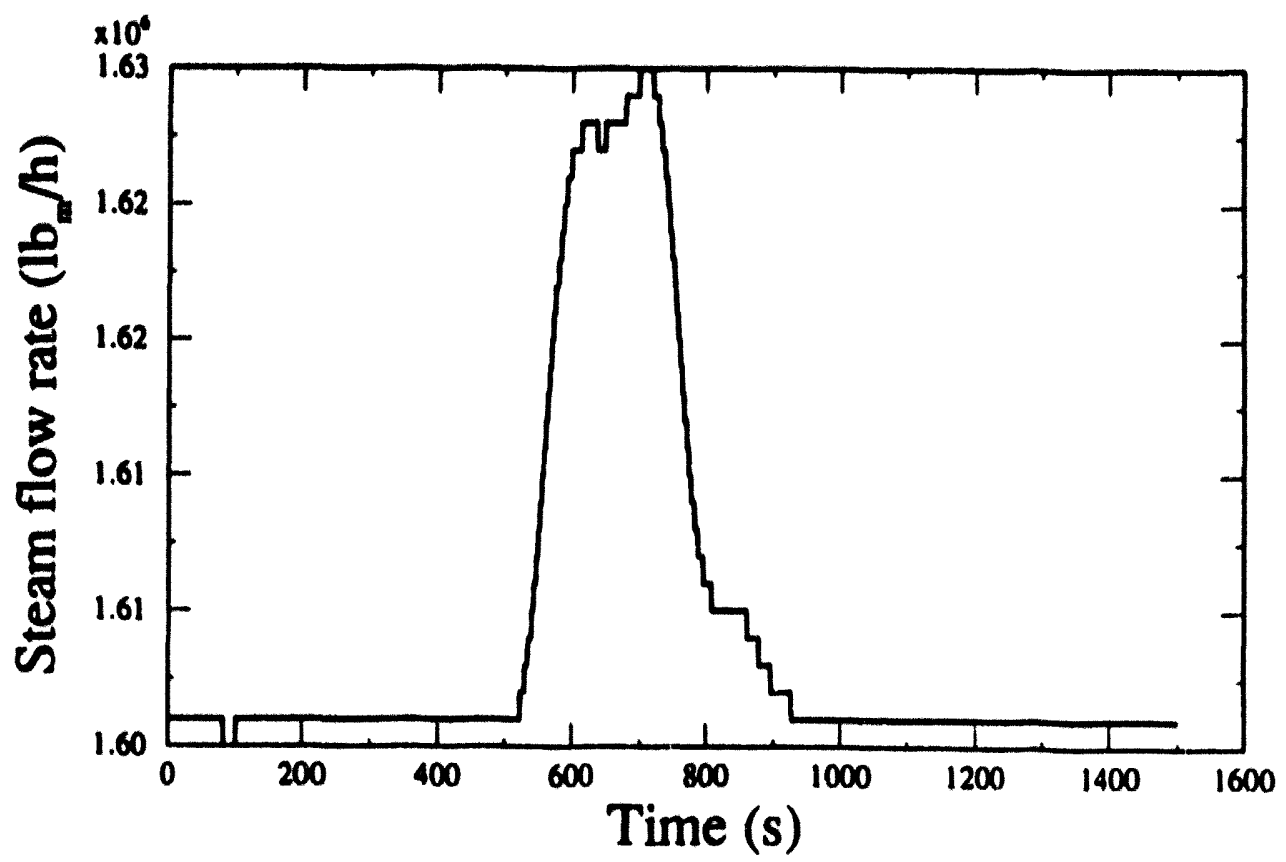

Fig. 14. Steam now rate during the $10 \%$ increase in primary coolant flow rate transient. 


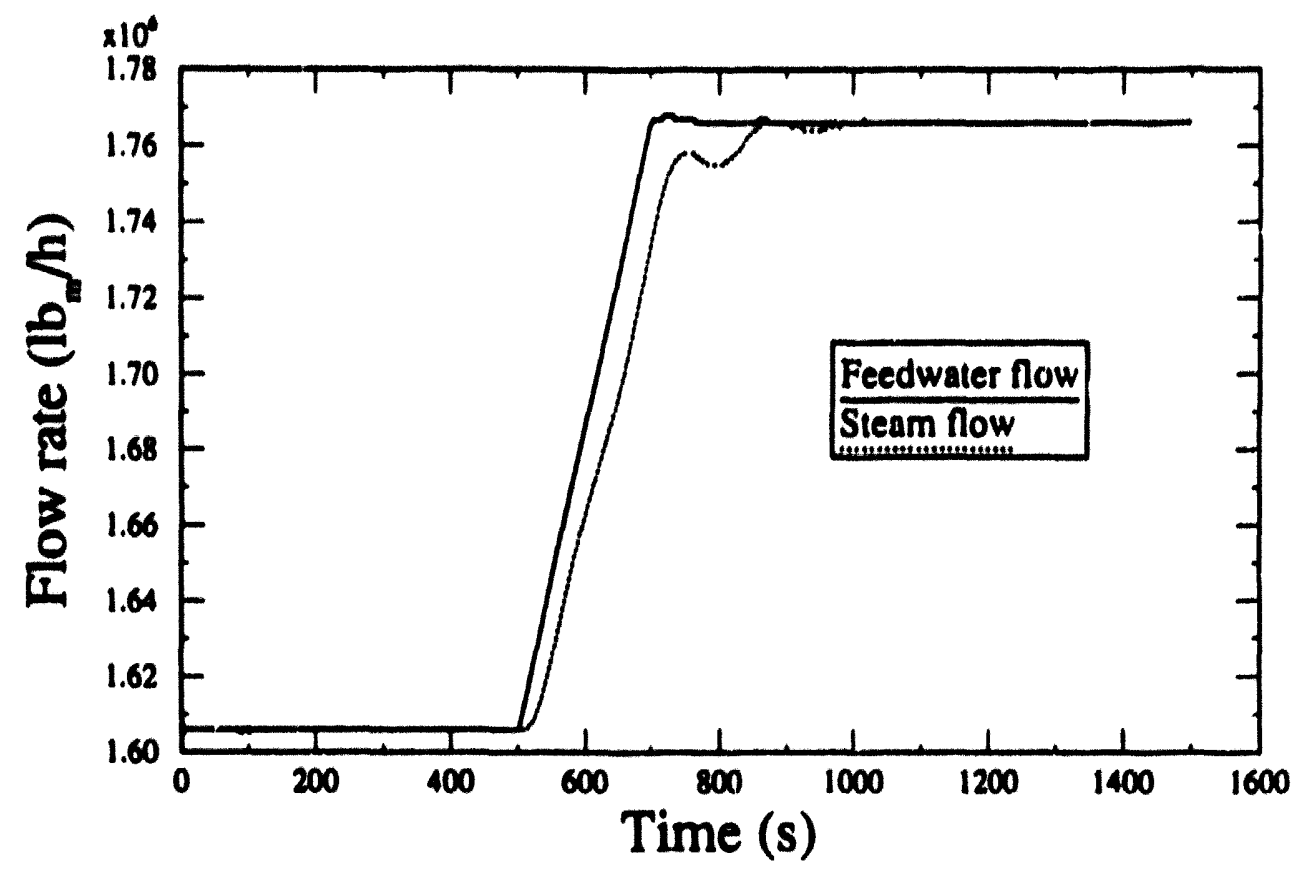

Fig. 15. Steam flow rate during the $10 \%$ increase in feedwater now rate transient.

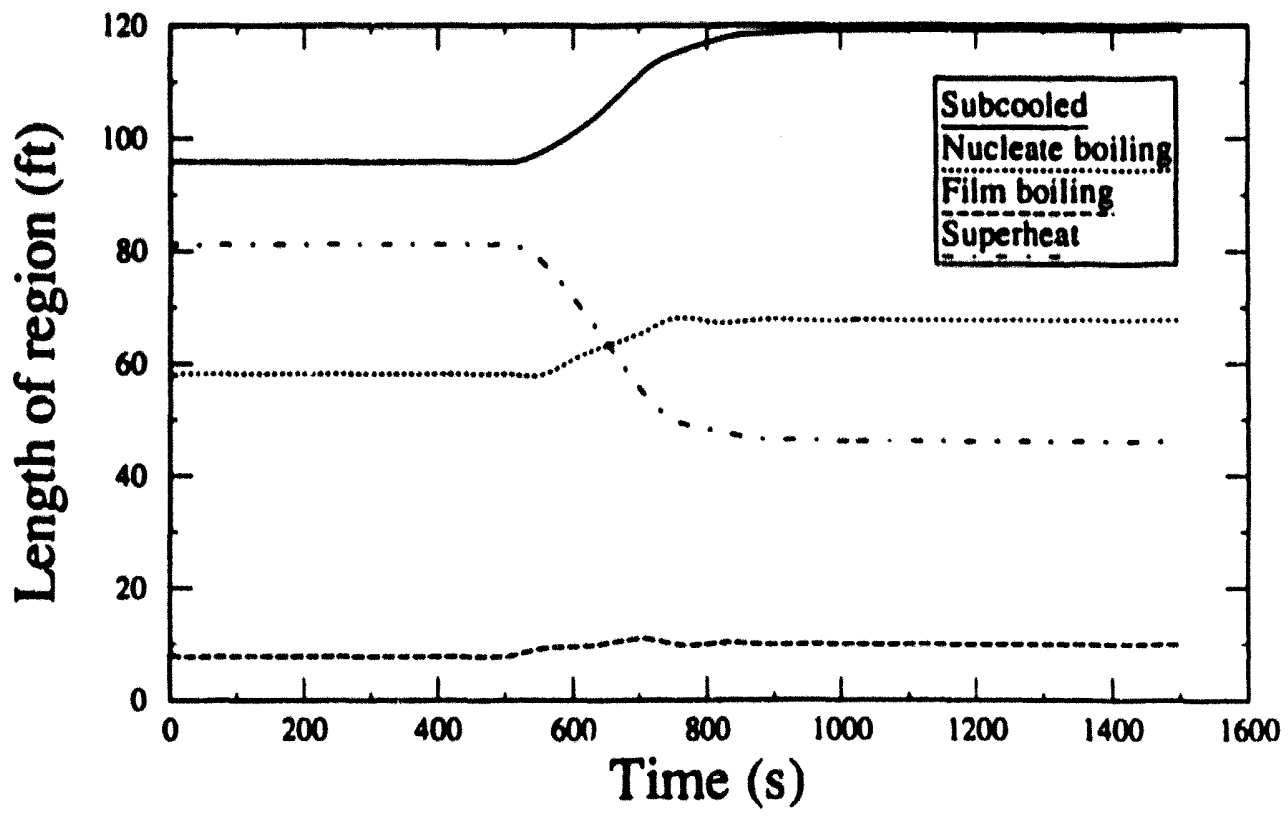

Fig. 16. Lengths of the subcooled, nucleate boiling, film boiling and superheat regions during the $10 \%$ increase in feedwater flow rate transient. 


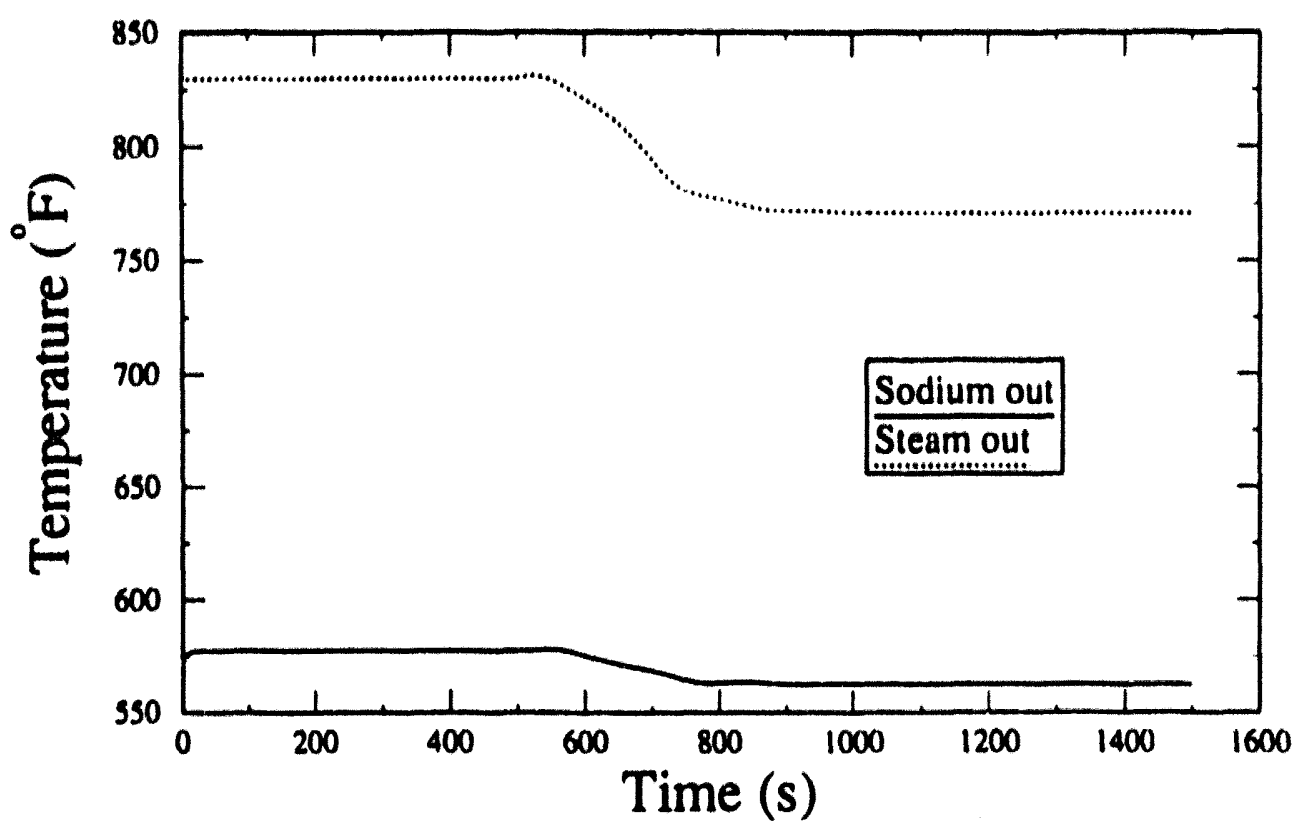

Fig. 17. Temperature of the outgoing steam and outgoing sodium during the $10 \%$ increase in feedwater flow rate transient.

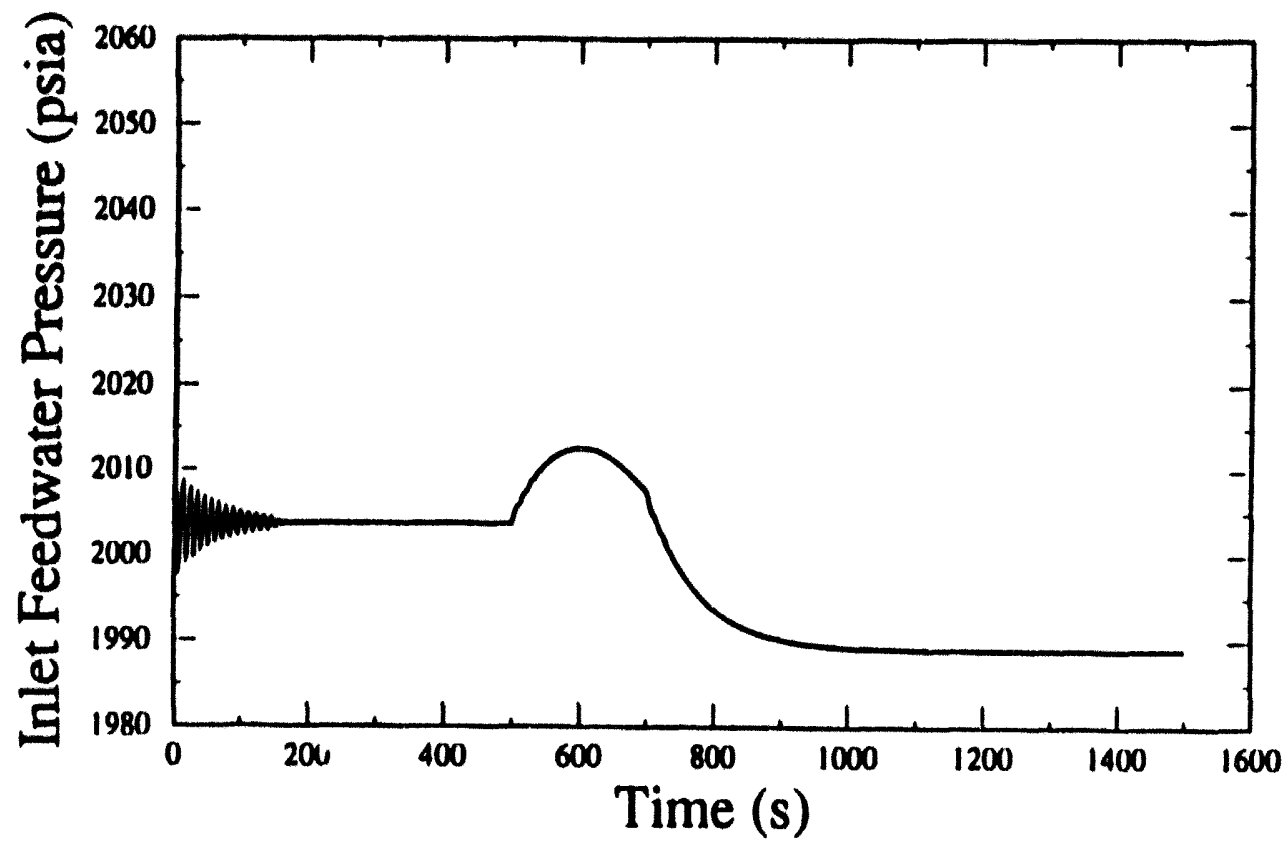

Fig. 18. Feedwater inlet pressure during the $10 \%$ increase in feedwater flow rate transient. 


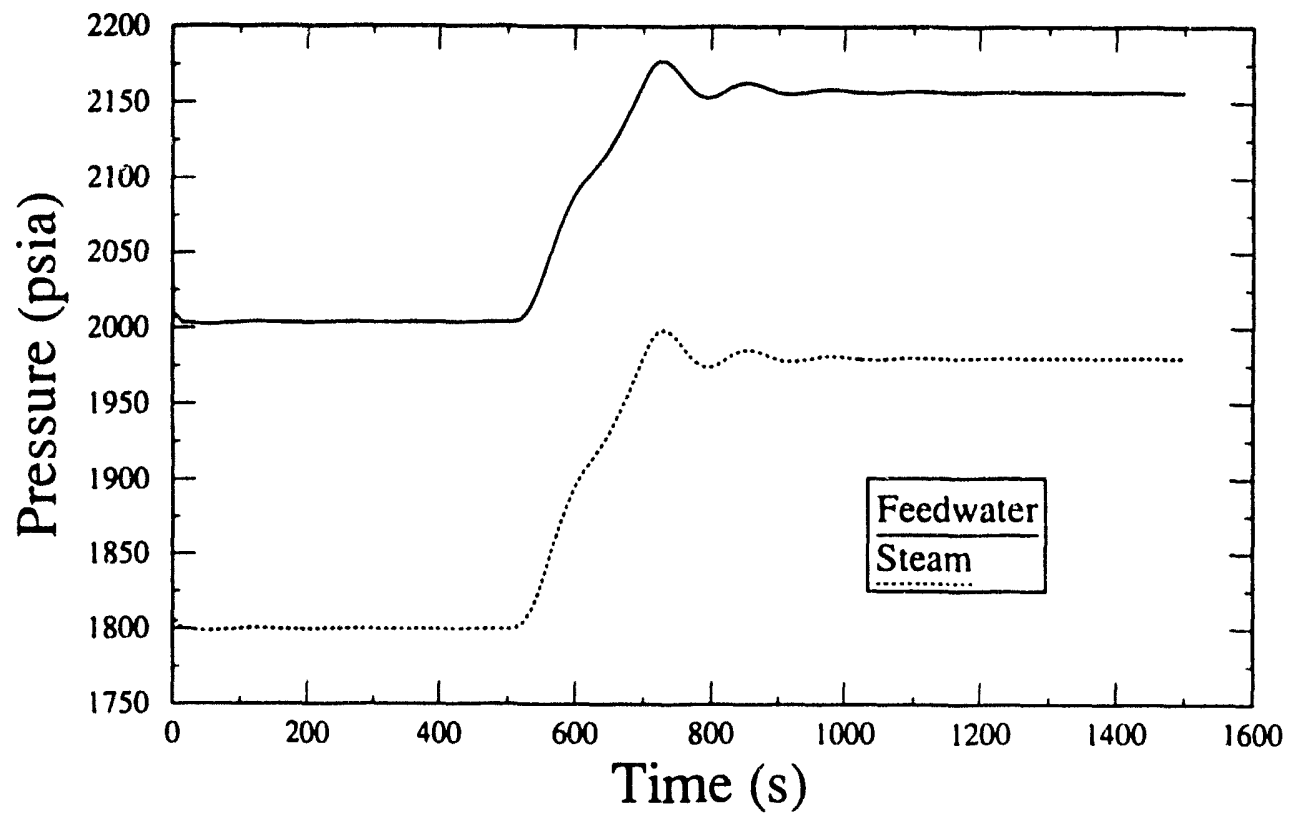

Fig. 19. Feedwater inlet pressure and steam outlet pressure during the $10 \%$ increase in outlet steam pressure transient.

boiling regions. Figure 20 depicts the length of each of the four regions during the transient. The increase in the steam header pressure causes a decrease in the flow rate of the steam out of the steam generator. As shown in Fig. 21, the steam flow rate settles down to its original value because there is no change in the inlet feedwater flow rate.

\section{5 $80 \%$ DECREASE IN FEEDWATER FLOW TRANSIENT}

To illustrate the capability of the model to study large load changes, the simulation results of a feedwater mass flow reduction from 100 to $20 \%$ are shown in Figs. 22-25. Figure 22 depicts the feedwater and steam flow rates during the transient. The feedwater flow is maintained at $1605600 \mathrm{lb} / \mathrm{h}$ for $500 \mathrm{~s}$ and then is ramped down to $321120 \mathrm{lb} / \mathrm{m}$ in $200 \mathrm{~s}$, after which it is maintained at the new rate for the remainder of the transient. As shown, a slight lag occurs after which the steam flow matches the decreased feedwater flow. For a constant primary flow rate and sodium inlet temperature, the decrease in feedwater flow resulted in an increase in the system temperatures. Figure 23 represents the outgoing sodium and steam temperatures during the transient. Figure 24 depicts the length of each of the four secondary side regions during the transient. The decrease in feedwater flow leads to a decrease in the length of the subcooled, nucleate boiling, and film boiling regions and an increase in the length of the superheat region. The primary and secondary heat transfer rates during the transient are shown in Fig. 25 . The $80 \%$ decrease in feedwater flow resulted in an $~ 80 \%$ decrease in both heat transfer rates from $1.6281 \times 10^{9}$ to $3.3312 \times 10^{8} \mathrm{Btu} / \mathrm{h}[477.2$ to $97.64 \mathrm{MW}(\mathrm{t})]$. 


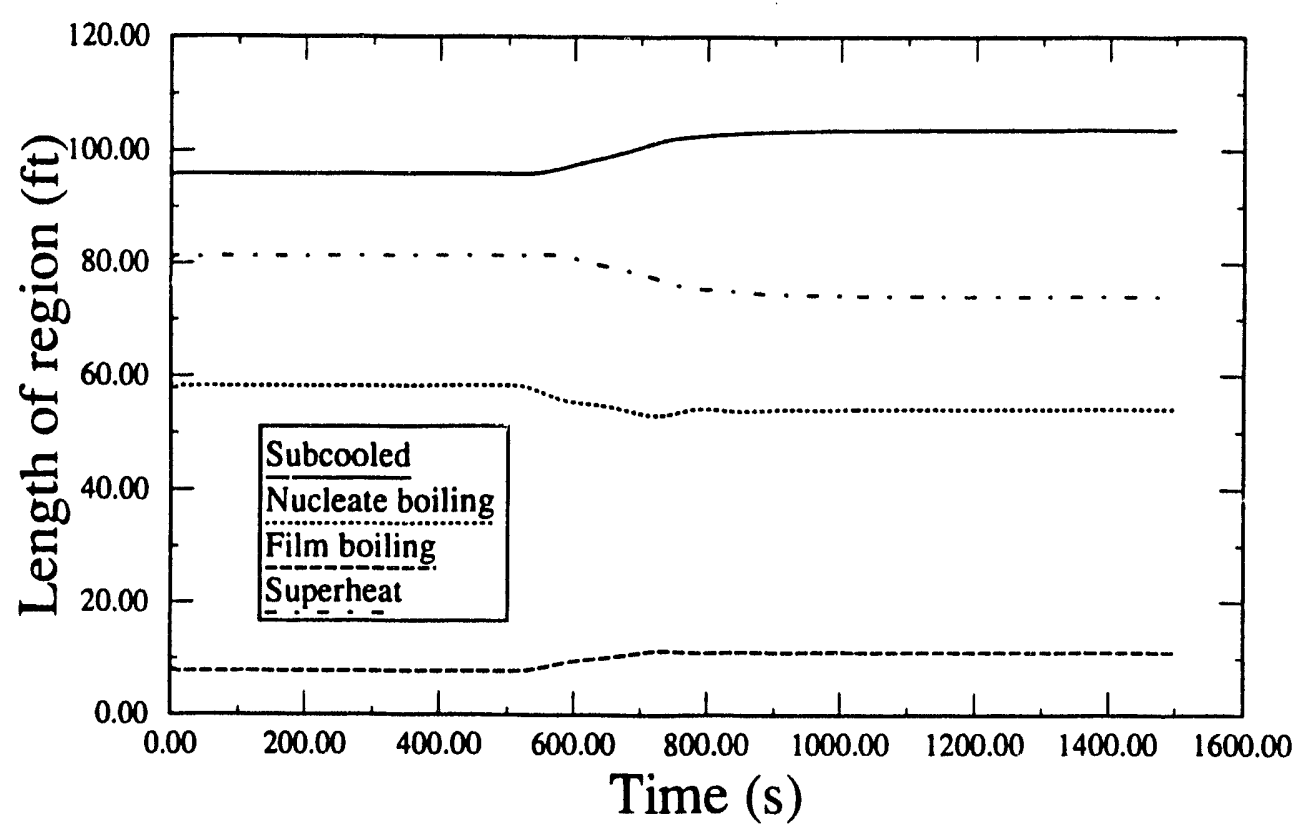

Fig. 20. Lengths of the subcooled, nucleate boiling, film boiling and superheat regions during the $10 \%$ increase in outlet steam pressure transient.

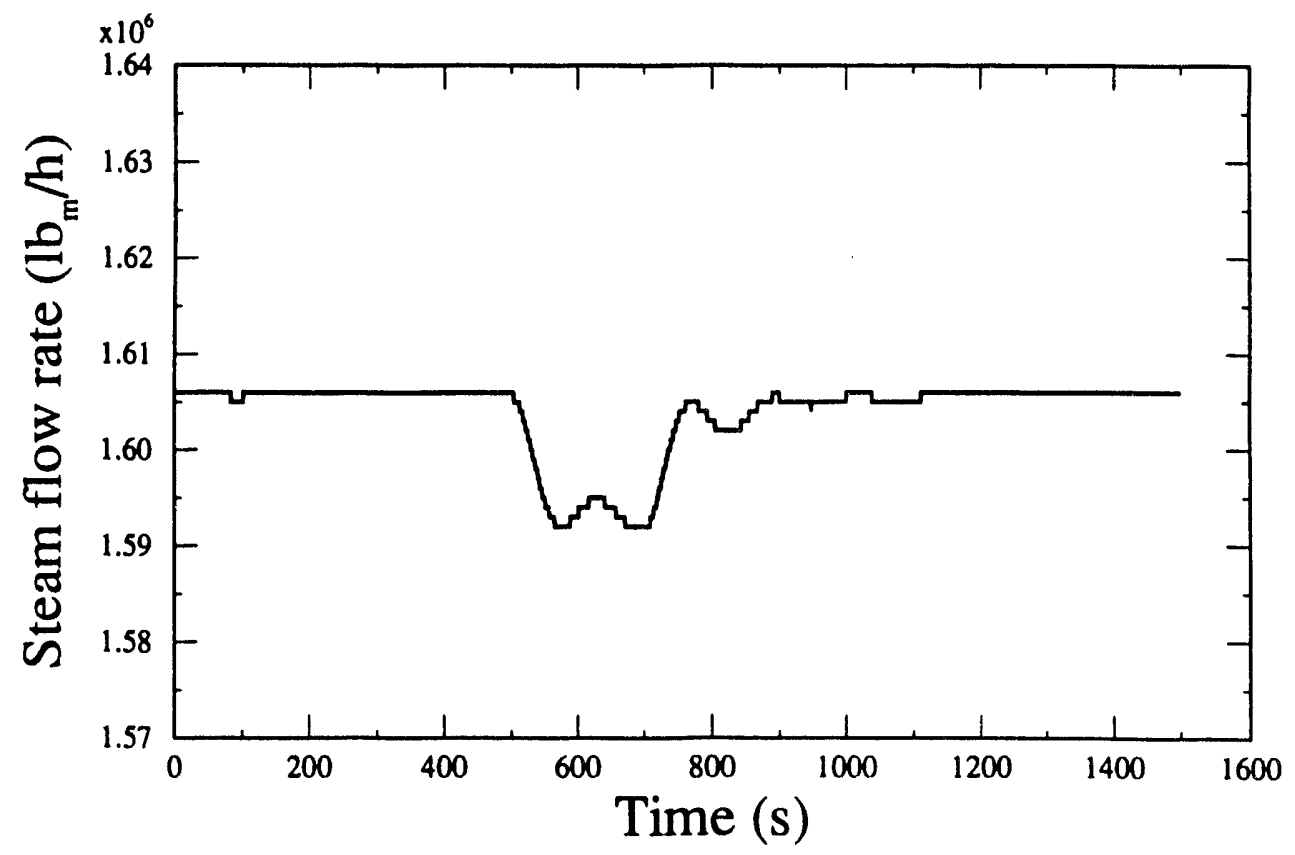

Fig. 21. Steam flow rate during the $10 \%$ increase in outlet steam pressure transient. 


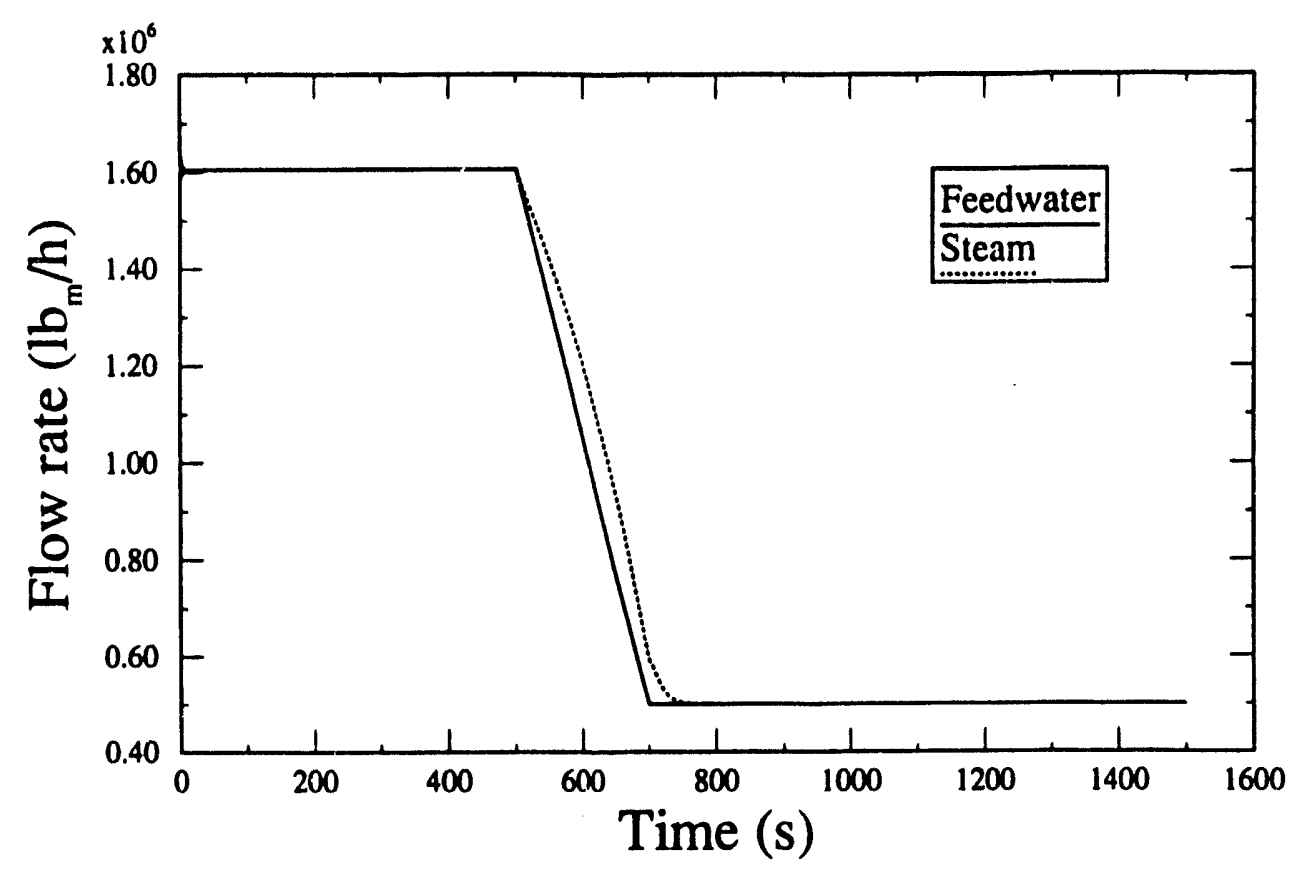

Fig. 22. Feedwater and steam flow rates during the $80 \%$ decrease in feedwater flow rate transient.

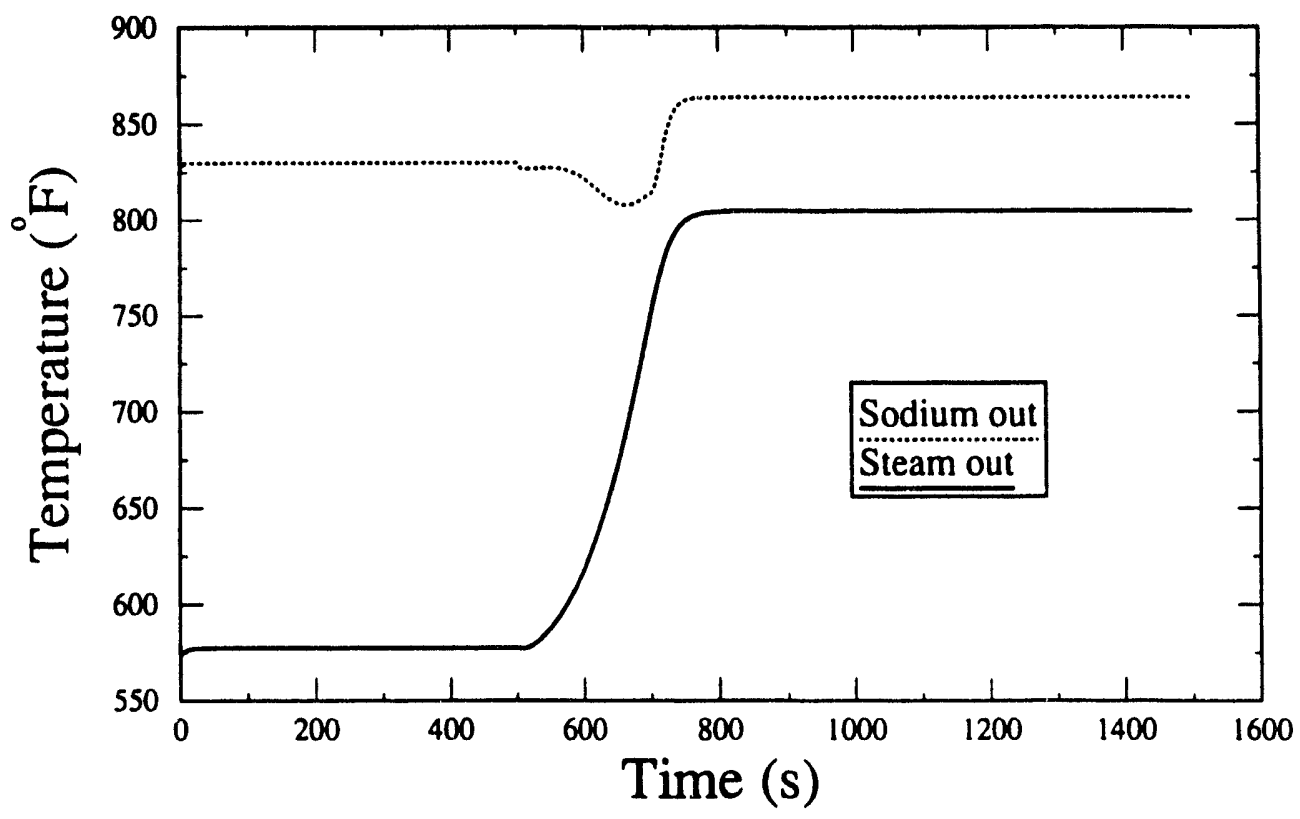

Fig. 23. Outgoing sodium and steam temperatures during the $80 \%$ decrease in feedwater flow rate transient. 


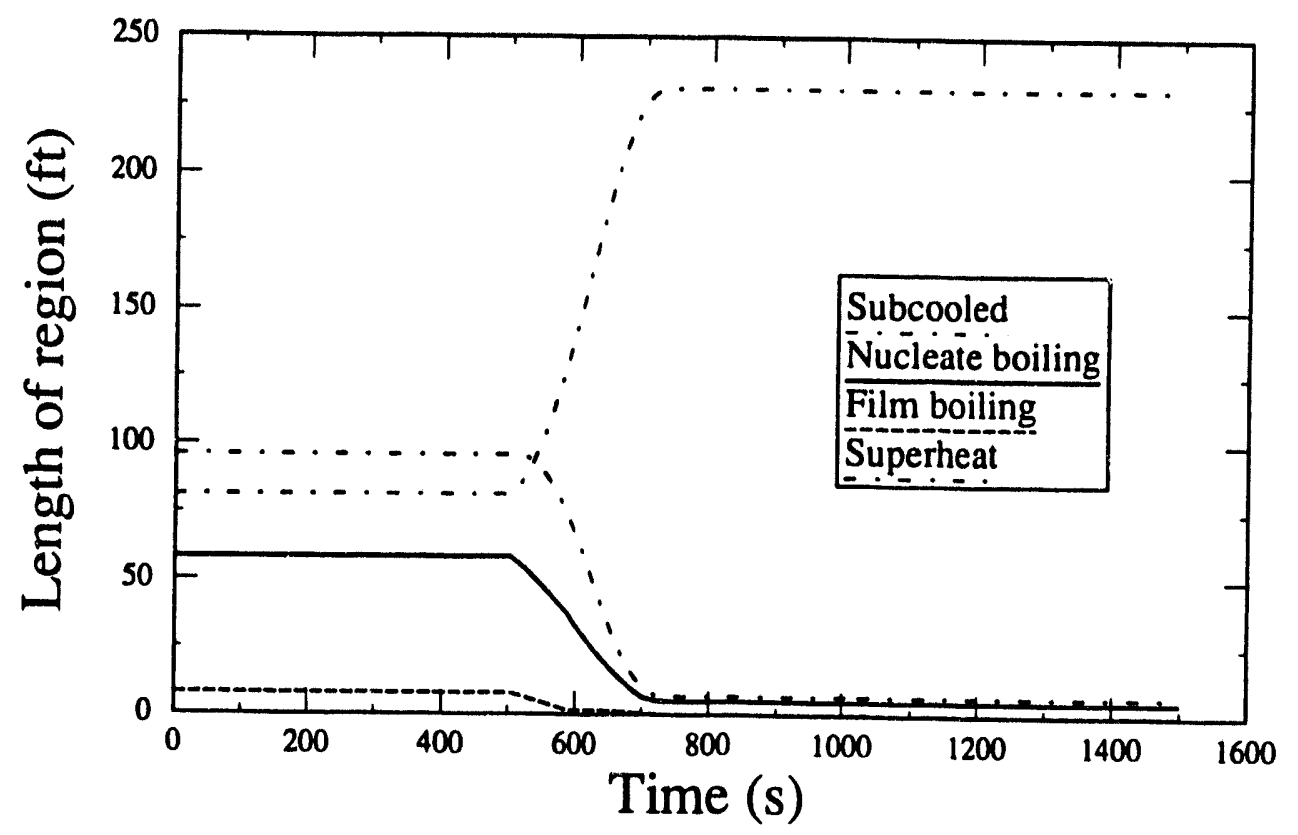

Fig. 24. Lengths of the subcooled, nucleate boiling, film boiling and superheat regions during the $80 \%$ decrease in feedwater flow rate transient.

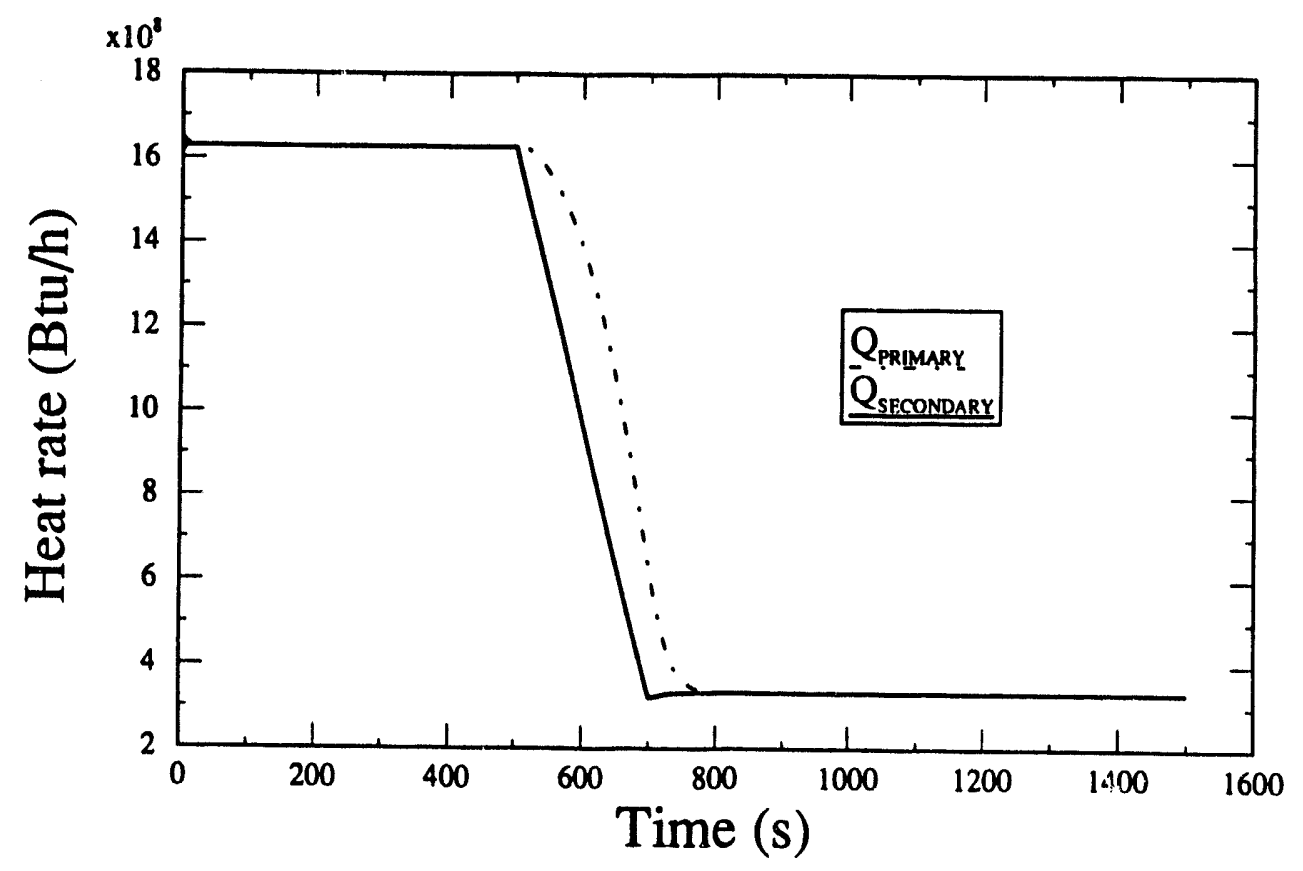

Fig. 25. Primary and secondary heat transfer rates during the $\mathbf{8 0 \%}$ decrease in feedwater flow transient. 


\section{CONCLUSIONS}

A four-region dynamic model of a once-through, helical-coil steam generator with moving boundaries has been presented. The steam generator under consideration is of the type used in the advanced liquid metal reactor in its superheat steam cycle design.

The model was tested for a number of transients. The results indicate that the model retains the main characteristics and is capable of simulating properly the dynamic response of the steam generator for a wide range of conditions. The system transients derived from the model are useful in the design of appropriate control systems.

The model can be used for flow stability studies, and it can also be used as an element in an overall system performance study of large-scale nuclear power plants. 


\section{ACKNOWLEDGMENTS}

The author acknowledges T. L. Wilson and S. J. Ball for providing valuable consultation and advice throughout this work. 


\section{REFERENCES}

1. M. Hui et al., 1991 ALMR Steam Cycle Study, GEFR-00899 UC-91Ta, August 1991. (This document is classified as "applied technology" and is not in the public domain. Requests for this document should be made through the U.S. Department of Energy, Washington, D.C.)

2. C. R. Kakarala and C. E. Boardman, "Advanced Liquid Metal Reactor Helical Coil Steam Generator," Thermal Hydraulics of Advanced Heat Exchangers, NE. Vol. 5. The American Society of Mechanical Engineers.

3. Advanced Continuous Simulation Language (ACSL), Mitchell \& Gauthier, Concord, Mass., 1991.

4. D. J. Nypaver, M. A. Abdalla, and L. Guimaraes, GOOSE 1.4 Generalized Object Oriented Simulation Environment: User's Manual, ORNL/TM-12267, Oak Ridge National Laboratory, November 1992.

5. N. Zuber and J. A. Findlay, "Average Volumetric Concentration in Two-Phase Flow Systems," J. Heat Transfer (1965).

6. M. Bein and R. Yahalom, "Dynamic Simulation of an LMFBR Steam Generator," 2nd Power Plant Dynamics, Control and Testing Symposium, Knoxville. Tennessee, USA, September (1975).

7. R. L. Burden, J. D. Faires, and A. C. Reynolds, Numerical Analysis, 2nd Ed.. Prindle, Weber \& Schmidt, Boston, 1981.

8. R. C. Martinelli and D. B. Nelson, "Prediction of Pressure Drop During Forced Circulation Boiling of Water," Trans. ASME, 70 (1948).

9. R. T. Lahey and F. J. Moody, The Thermal Hydraulics of A Boiling Water Nuclear Reactor, American Nuclear Society, 1979.

10. J. R. S. Thom, "Prediction of Pressure Drop During Forced Circulation Boiling of Water," Int. J. Heat Mass Transfer, 7 (1964).

11. A. Bishop et al., "Forced Convection Heat Transfer at High Pressure after the Critical Heat Flux," Trans. ASME, 65, HT (1965).

12. N. W. S. Bruens et al., "Modeling of Steam Generator Dynamics," 2nd Power Plant Dynamics, Control and Testing Symposium, Knoxville, Tennessee, USA, September (1975).

13. "Modular Modeling System (MMS): A Code for the Dynamic Simulation of Fossil and Nuclear Power Plants," Vol. 1. Theory Manual B\&WIEPRI Computer Code Manual, March 1985. 
Appendix A.

ELEMENTS OF THE A AND B MATRICES 


$$
\begin{aligned}
& a_{11}=3600 v_{1} \bar{p}_{1} \\
& a_{18}=-666.186 V_{1} \\
& a_{21}=3600 V_{1} \frac{\partial \bar{\rho}_{1}}{\partial h} \\
& a_{22}=3600 \mathrm{~A}_{\mathrm{s}} \overline{\rho_{1}} \\
& a_{28}=3600 V_{1} \frac{\partial \overline{p_{1}}}{\partial p} \\
& a_{32}=-3600 \overline{\rho_{2} h_{2}} A_{s} \\
& a_{33}=3600 \overline{\rho_{2} h_{2}} A_{s} \\
& a_{3 s}=1 \times 10^{6} h_{2} \\
& a_{38}=V_{2}\left[\begin{array}{l}
3600\left(\rho_{8} h_{1}-\rho_{1} h_{1}\right)\left(\frac{\partial \overline{\alpha_{2}}}{\partial \mathrm{P}}+\frac{\partial \overline{\alpha_{2}}}{\partial \mathrm{X}} \frac{\partial \mathrm{X}}{\partial \mathrm{P}}\right) \\
+\overline{\alpha_{2}}\left(\rho_{1} \frac{\partial h_{1}}{\partial \mathrm{P}}+h_{1} \frac{\partial \rho_{8}}{\partial \mathrm{P}}\right) \\
+\left(1-\bar{\alpha}_{2}\right)\left(\rho_{1} \frac{\partial h_{1}}{\partial \mathrm{P}}+h_{1} \frac{\partial \rho_{1}}{\partial \mathrm{P}}\right)-666.186
\end{array}\right] \\
& a_{42}=-3600 \overline{\rho_{2}} A_{s} \\
& a_{43}=3600 \overline{\rho_{2}} A_{s} \\
& a_{45}=1 \times 10^{6} \\
& a_{48}=3600 v_{2}\left[\begin{array}{l}
\left(\rho_{8}-\rho_{1}\right)\left(\frac{\partial \bar{\alpha}_{2}}{\partial \mathrm{P}}+\frac{\partial \bar{\alpha}_{2}}{\partial \mathrm{X}} \frac{\partial \mathrm{X}}{\partial \mathrm{P}}\right) \\
+\bar{\alpha}_{2} \frac{\partial \rho_{8}}{\partial \mathrm{P}}+\left(1-\bar{\alpha}_{2}\right) \frac{\partial \rho_{1}}{\partial \mathrm{P}}
\end{array}\right]
\end{aligned}
$$




$$
\begin{aligned}
& a_{93}=3600 \mathrm{~A}, \overline{\rho_{3} h_{3}} \\
& a_{34}=-3600 A_{s} \overline{\rho_{3} h_{3}} \\
& a_{s s}=1 \times 10^{6} \\
& a_{36}=-1 \times 10^{6}
\end{aligned}
$$

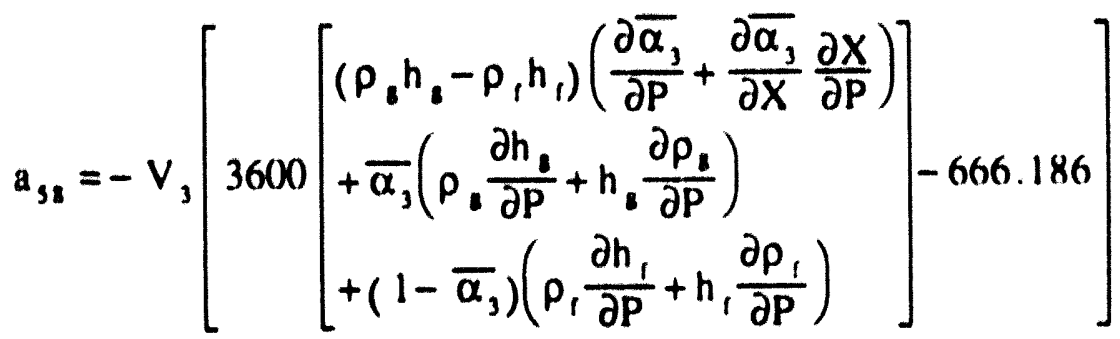

$$
\begin{aligned}
& a_{63}=3600 \overline{p_{3}} A_{3} \\
& a_{64}=-3600 \overline{\rho_{3}} A_{s} \\
& a_{65}=1 \times 10^{6} \\
& a_{66}=-1 \times 10^{6} \\
& a_{68}=-3600 v_{3}\left[\begin{array}{l}
\left(\rho_{1}-\rho_{1}\right)\left(\frac{\partial \bar{\alpha}_{3}}{\partial P}+\frac{\partial \bar{\alpha}_{3}}{\partial X} \frac{\partial X}{\partial P}\right) \\
+\bar{\alpha}_{3} \frac{\partial \rho_{8}}{\partial P}+\left(1-\bar{\alpha}_{3}\right) \frac{\partial \rho_{1}}{\partial P}
\end{array}\right] \\
& a_{76}=\left(\overline{h_{4}}-h_{3}\right) \times 10^{6} \\
& a_{71}=3600 \overline{p_{4}} V_{4} \\
& a_{78}=-666.186 V_{4} \\
& a_{84}=3600 \overline{\rho_{4}} A_{s} \\
& a_{86}=1 \times 10^{6}
\end{aligned}
$$




$$
\begin{aligned}
& a_{31}=-3600 v_{4}\left(\frac{\partial \rho_{1}}{\partial h}\right) \\
& a_{11}=-3600 v_{4}\left(\frac{\partial \rho_{1}}{\partial p}\right) \\
& b_{1}=W_{s E}\left(h_{s E}-\bar{h}_{1}\right) \\
& b_{2}=W_{3 E}-\frac{Q_{13}}{\left(h_{1}-h_{1}\right)} \\
& b_{3}=Q_{2 s}+\frac{Q_{13} h_{1}}{\left(h_{1}-h_{1}\right)}-3600 v_{2}\left(\rho_{2} h_{1}-\rho_{1} h_{1}\right)\left(\frac{\partial \overline{\alpha_{2}}}{\partial G}+\frac{\partial \overline{\alpha_{2}}}{\partial X} \frac{\partial X}{\partial \bar{G}}\right) \frac{d G}{d t} \\
& b_{4}=\frac{Q_{1 s}}{\left(h_{1}-h_{1}\right)}-3600 v_{2}\left(\rho_{1}-\rho_{1}\right)\left(\frac{\partial \overline{\alpha_{2}}}{\partial G}+\frac{\partial \overline{\alpha_{2}}}{\partial X} \frac{\partial X}{\partial G}\right) \frac{d G}{d t} \\
& h_{3}=3600 v_{3}\left(p_{2} h_{2}-p_{1} h_{1}\right)\left(\frac{\partial \overline{\alpha_{3}}}{\partial G}+\frac{\partial \overline{\alpha_{3}}}{\partial X} \frac{\partial X}{\partial G}\right) \frac{d G}{d t}-Q_{3 s} \\
& b_{6}=3600 v_{3}\left(p_{1}-p_{1}\right)\left(\frac{\partial \overline{\alpha_{3}}}{\partial G}+\frac{\partial \overline{\alpha_{3}}}{\partial X} \frac{\partial X}{\partial G}\right) \frac{d G}{d l} \\
& b_{7}=Q_{45}-W_{s t .}\left(h_{4}-\overline{h_{4}}\right) \\
& b_{1}=W_{s L}
\end{aligned}
$$




\section{INTERNAL DISTRIBUTION}

1-7. M. A. Abdalla

8-10. S. J. Ball

11. H. R. Brashear

12-16. C. R. Brittain

17. N. E. Clapp, Jr.

18. D. F. Craig

19. B. G. Eads

20. D. N. Fry

21. J. March-Leuba

22. J. K. Mattingly

23. D. W. McDonald

24. D. R. Miller

25. G. N. Miller

26. J. K. Munro, Jr.
27. R. B. Perez

28. J. S. Powell

29. O. L. Smith

30. J. O. Stiegler

31. T. L. Wilson

32. B. K. Swail

33. R. E. Uhrig

34. J. D. While

35. R. T. Wood

36- 37. Central Research Library

38. Y.12 Technical Reference Section

39-40. Laboratory Records

41. Laboratory Records-RC

42. ORNL Patent Section

43. I\&C Division Publications Office

\section{EXTERNAL DISTRIBUTION}

44. Assistant Manager for Energy Research and Development, DOE-ORO, P.O. Box 2001, Oak Ridge TN 37831.8600

45. B. Chexal, Electric Power Research Institute, 3412 Hillview Avenue, Palo Alto, CA 94303

46. V. Radeka, Brookhaven National Laboratory, Instrumentation Division, 535B, Upton, NY 11973

47. M. M. Sevik, Carderock Division, Naval Surface Warfare Center, Code 1900, Bethesda, MD 20084.5000

48. R. M. Taylor, Leeds and Northup, Sunneytown Pike, North Wales, PA 19454

49. Y. Dayal, GE Nuclear Energy, Advanced Nuclear Technology, 68.35 Via Del Oro, San Jose, CA 95119.1315

50. E. L. Gluekler, GE Nuclear Energy, Nuclear Systems Technology Operation, 6835 Via Del Oro, San Jose, CA 95119.1315

51. W. K. Wagner, GE Nuclear Energy, Nuclear Systems Technology Operation, P. O. Box 530954, San Jose, CA 95153-5354

52. H. P. Planchon, Argonne National Laboratory, 97(X) South Cass Avenue, Argonne, IL 60439

53. J. I. Sackett, Argonne National Laboratory, 9700 South Cass Avenue, Argonne, IL 60439 
54. J. W. Cooke, Energy Programs Division, DOE-ORO, P.O. Box 2(k)1, Oak Ridge. TN $37831.86(\mathrm{X})$

55. D. Ugolini, Via Pacinotti 29, Cesena (FO) 47()23, laaly

56. T. W. Kerlin, The University of Tennessee, Nuclear Engineering Department. Knoxville, TN 37996-23(x)

57. L. Guimaraes, Centro Tecnico Aerospacial, Instituto de Estudios Avanzados/ENU, Caixa Postal 6(1444, Sao Jose Campos, SP 122.31, Brazil

58. C. March-Leuba, INITEC, Padilla 17, Madrid 28()()6, Spain

59-114. Given distribution as shown in DOE/OSTI.45()() under Category UC -53() . Liquid Metal Fasi Breeder Reactors 

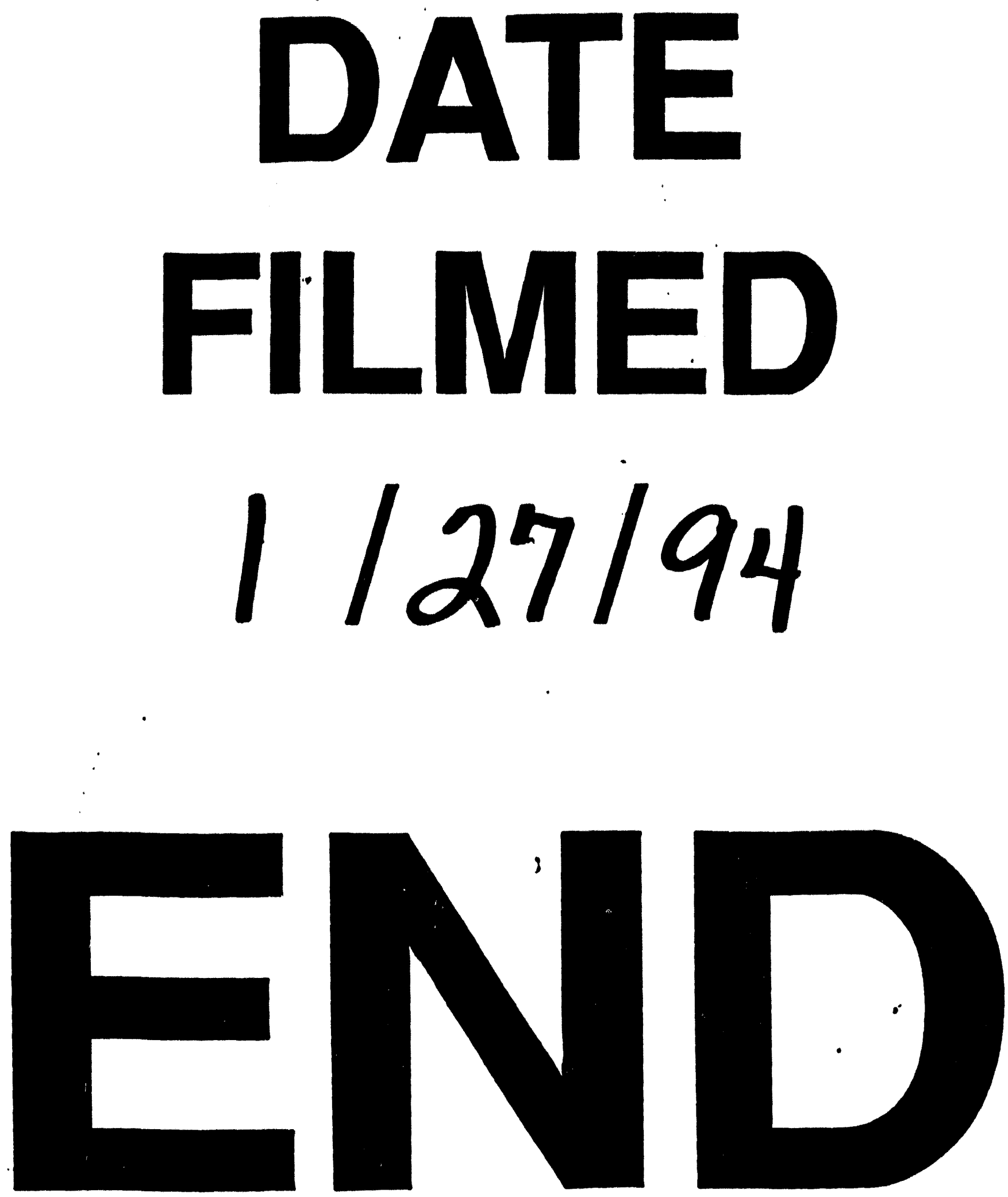